VICENTE GODOY DE SALLES OLIVEIRA SILVA

Situação Epidemiológica da Brucelose Bovina no Estado de Sergipe

São Paulo

2008 


\title{
Situação Epidemiológica da Brucelose Bovina no Estado de Sergipe
}

\author{
Dissertação apresentada ao Programa de Pós- \\ graduação em Epidemiologia Experimental e \\ Aplicada às Zoonoses da Universidade de São Paulo \\ para obtenção do título de Mestre em Medicina \\ Veterinária
}

Departamento:

Medicina Veterinária Preventiva e Saúde Animal

Área de concentração:

Epidemiologia Experimental e Aplicada às Zoonoses

Orientador:

Prof. Dr. José Soares Ferreira Neto

São Paulo 
Autorizo a reprodução parcial ou total desta obra, para fins acadêmicos, desde que citada a fonte.

DADOS INTERNACIONAIS DE CATALOGAÇÃO-NA-PUBLICAÇÃO

(Biblioteca Virginie Buff D’Ápice da Faculdade de Medicina Veterinária e Zootecnia da Universidade de São Paulo)

T.2048 Silva, Vicente Godoy de Salles Oliveira

FMVZ Situação epidemiológica da brucelose bovina no Estado de Sergipe / Vicente Godoy de Salles Oliveira Silva. - São Paulo : V. G. S. O. Silva, 2008.

$55 \mathrm{f}$ : : il

Dissertação (mestrado) - Universidade de São Paulo. Faculdade de Medicina Veterinária e Zootecnia. Departamento de Medicina Veterinária Preventiva e Saúde Animal, 2008.

Programa de Pós-Graduação: Epidemiologia Experimental e Aplicada às Zoonoses.

Área de concentração: Epidemiologia Experimental e Aplicada às Zoonoses.

Orientador: Prof. Dr. José Soares Ferreira Neto.

1.Brucelose. 2. Bovinos. 3. Prevalência. 4. Sergipe. 5. Brasil. I. Título. 


\section{UNIVERSIDADEDE SAO PAULO \\ Faculdade de Medicina Veterinaria c Zoolocula

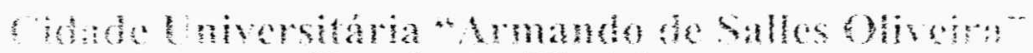 \\ Comissão Bioética \\ CERTIFICADO}

Certificamos que o Projeto intitulado "Epidemiologia e controle da brucelose e tuberculose bovinas no Brasil: bases para as intervençoes", protocolo $n^{\circ} 441 / 2004$, utilizando 180 hamsters, sob a responsabilidade do Prof. Dr. José Soares Ferreira Neto, está de acordo com os princípios éticos de experimentação animal da Comissão de Bioética da Faculdade de Medicina Veterinária e Zootecnia da Universidade de São Paulo e foi aprovado pela referida Comissão em sessão de $14 / 04 / 04$.

We certify that the Research "Epidemiology and contrl of the hovine brucellosis and tuberculosis in Brazil: basis for the interventions" protocol number 441/2004, utilizing 180 hamsters, under the responsibility of Prof Dr. José Soares Ferreira Neto, agree with Ethical Principles in Animal Resedwi adopted by Bioethic Commission of the Faculty of Veterinar Medicine and Zootechny of University of São Paulo and was approved in $04 / 14 / 2004$ meeting.

Sào Paulo, 16 de abril de 2004

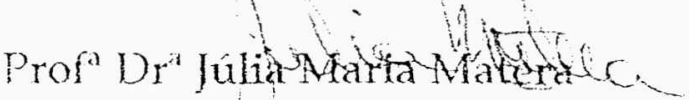

Presidente da Comissão de Bioética FMLZ/USP 


\section{FOLHA DE AVALIAÇÃO}

Nome do autor: SILVA, Vicente Godoy de Salles Oliveira

Título: Situação Epidemiológica da Brucelose Bovina no Estado de Sergipe

Dissertação apresentada ao Programa de Pósgraduação em Epidemiologia Experimental e Aplicada às Zoonoses da Faculdade de Medicina Veterinária e Zootecnia da Universidade de São Paulo para obtenção do título de Mestre em Medicina Veterinária

Data:

Banca Examinadora

Prof. Dr.

Instituição:

Assinatura:

Julgamento:

Prof. Dr.

Instituição:

Assinatura:

Julgamento:

Prof. Dr.

Instituição:

Assinatura:

Julgamento: 


\section{Dedicatória}

Dedico este trabalho aos meus pais

Raul, um exemplo de pai e amigo

Vera Lúcia, uma vida dedicada aos filhos

Aos meus irmãos

Priscila

Vinicius

E à minha sobrinha Sofia 


\section{Agradecimentos}

Ao meu orientador Prof. Dr. José Soares Ferreira Neto, Zezé, por aceitar me orientar e me proporcionar uma vivência única, dentro dessa maravilhosa Universidade

Aos professores Doutores, Ricardo Augusto Dias, Fernando Ferreira e Marcos Amaku, pela paciência e atenção dispensada durante a elaboração das análises

A Jucélia, sempre pronta a auxiliar os pós-graduandos

A todos os colegas do LEB e do VPS, pela ótima convivência, troca de experiências e informações.

Aos professores do VPS em que tive o imenso prazer de assistir as aulas

Ao Luis Felipe, que dá sentido à palavra amigo. 


\section{RESUMO}

SILVA, V. G de S. O. Situação epidemiológica da brucelose bovina no Estado de Sergipe, Brasil. [Epidemiological situation of bovine brucellosis in Sergipe State, Brazil]. 2008. 55 f. Dissertação (Mestrado em Medicina Veterinária) - Faculdade de Medicina Veterinária e Zootecnia, Universidade de São Paulo, São Paulo, 2008.

Para dar suporte à implementação do Programa Nacional de Controle e Erradicação da Brucelose no Estado do Sergipe, foi realizado um estudo para caracterizar a situação epidemiológica da doença. Assim, o Estado foi estratificado em 2 circuitos produtores. Em cada circuito produtor foram amostradas aleatoriamente cerca de 300 propriedades e, dentro dessas foi escolhido de forma aleatória um número pré-estabelecido de animais, dos quais foi obtida uma amostra de sangue. No total foram amostrados 4.757 animais, provenientes de 590 propriedades. Em cada propriedade amostrada foi aplicado um questionário epidemiológico indagando sobre a tipologia da propriedade e sobre práticas zootécnicas e sanitárias que poderiam estar associadas ao risco de infecção pela doença. O protocolo de testes utilizado foi a triagem com o teste do Antígeno Acidificado Tamponado e confirmação dos positivos com o teste do 2-Mercaptoetanol. O rebanho foi considerado positivo, se pelo menos um animal fosse reagente às duas provas sorológicas. As prevalências de focos e nos animais do Estado foram de 12,60\% [9,19 - 16,01\%] e 3,36\% [2,28 - 4,44\%]. As prevalências de focos e animais para os circuitos produtores foram: circuito 1: 11,07\% [7,87 - 15,00 \%] e 2,58\% [1,62 - 3,54\%]. Circuito 2: $12,92 \%$ [9,12 - 17,59\%] e 6,25\% [3,00 - 9,49\%]. Os fatores de risco associados à condição de foco foram: assistência veterinária $(\mathrm{OR}=2,89 ;[1,15-7,23])$, tamanho do rebanho $\geq 30$ fêmeas adultas $(\mathrm{OR}=1,88 ;[1,07-3,28])$ e uso de inseminação $\operatorname{artificial}(\mathrm{OR}=1,92 ;[0,84-4,38])$.

Palavras-chave: Brucelose, bovinos, prevalência, fatores de risco, Sergipe, Brasil. 


\begin{abstract}
SILVA, V. G de S. O. Epidemiological situation of bovine brucellosis in Sergipe State, Brazil. [Situação epidemiológica da brucelose bovina no Estado de Sergipe, Brasil]. 2008. 55 f. Dissertação (Mestrado em Medicina Veterinária) - Faculdade de Medicina Veterinária e Zootecnia, Universidade de São Paulo, São Paulo, 2008.
\end{abstract}

To support the planning and implementation of the National Program for the Control and Eradication of Bovine Brucellosis in the State of Sergipe, a study to characterize the brucellosis epidemiological situation was carried out. The State was divided in two regions. Around three hundred herds were randomly sampled in each region, and a pre-established number of animals were sampled in each of these herds. A total of 4757 serum samples from 590 herds were collected. In each herd, it was applied an epidemiological questionnaire focused on herd traits as well as husbandry and sanitary practices that could be associated with the risk of infection. The serum samples were screened by the Rose-Bengal Test (RBT), and all test positives were re-tested by the 2-Mercaptoethanol Test (2-ME). The herd was considered positive if at least one animal tested positive on both RBT and 2-ME tests. The prevalence of infected herds and animals at the State level were respectively 12,60\% [9,19$16,01 \%]$ and 3,36\% [2,28 - 4,44\%]. The prevalence of infected herds and animals at the Regional level were respectively: region 1: 11,07\% [7,87 - 15,00\%] and 2,58\% [1,62 - 3,54 $\%]$, region 2: 12,92\% [9,12 - 17,59\%] and 6,25\% [3,00 - 9,49\%]. The factors associated with the presence of the infection were: veterinary assistance $(O R=2,89$ [1,15 -7,23]) and herd size $\geq 30$ adult females $(O R=1,88$ [1,07 - 3,28] and use of artificial insemination $(\mathrm{OR}=1,92 ;[0,84-4,38])$

Keywords: Brucellosis, cattle, prevalence, risk factors, Sergipe, Brazil. 


\section{LISTA DE MAPAS}

Mapa 1 - Mapa do Estado de Sergipe com representação dos circuitos produtores. São Paulo, 2008. 


\section{LISTA DE TABELAS}

Tabela 1 - Dados censitários da população bovina do Estado de Sergipe em 2001, segundo os circuitos produtores (cadastro do DEAGRO). São Paulo, 2008.

Tabela 2 - Prevalência de focos de brucelose bovina nos circuitos produtores do Estado de Sergipe. São Paulo, 2008

Tabela 3 - Prevalência de focos de brucelose bovina, segundo o tipo de exploração nos circuitos produtores do Estado de Sergipe. São Paulo, 2008

Tabela 4 - Prevalência de bovinos sororreagentes para brucelose nos circuitos produtores do Estado de Sergipe. São Paulo, 2008

Tabela 5 - Análise univariada dos possíveis fatores de risco para brucelose bovina em rebanhos com atividade reprodutiva no Estado de Sergipe. São Paulo, 2008.

Tabela 6 - Modelo final da regressão logística multivariada para os fatores de risco para brucelose bovina em rebanhos com atividade reprodutiva no Estado de Sergipe. São Paulo, 2008

Tabela 7 - Análise univariada dos possíveis fatores de risco para brucelose bovina em rebanhos com atividade reprodutiva do circuito produtor 1 do Estado de Sergipe. São Paulo, 2008 .

Tabela 8 - Modelo final da regressão logística multivariada para os fatores de risco para brucelose bovina em rebanhos com atividade reprodutiva do circuito produtor 1 do Estado de Sergipe. São Paulo, 2008

Tabela 9 - Análise univariada dos possíveis fatores de risco para brucelose bovina em rebanhos com atividade reprodutiva do circuito produtor 2 do Estado de Sergipe. São Paulo, 2008.

Tabela 10 - Modelo final da regressão logística multivariada para os fatores de risco para brucelose bovina em rebanhos com atividade reprodutiva do circuito produtor 2 do Estado de Sergipe. São Paulo, 2008

Tabela 11 - Frequência dos tipos de exploração em propriedades rurais segundo os circuitos produtores do Estado de Sergipe. São Paulo, 2008 
Tabela 12 - Frequência dos tipos de criação nas propriedades de corte, leite e mistas, segundo as regiões do Estado do Sergipe. São Paulo, 2008 .

Tabela 13 - Número de ordenhas por dia nas propriedades de leite e mistas segundo as regiões do Estado do Sergipe. São Paulo, 2008.

Tabela 14 - Frequência dos tipos de ordenha nas propriedades de leite e mistas, segundo as regiões do Estado do Sergipe. São Paulo, 2008

Tabela 15 - Produtividade de leite nas propriedades de leite e mistas, segundo regiões do Estado do Sergipe. São Paulo, 2008

Tabela 16 - Frequência de uso de inseminação artificial em propriedades de corte, leite e mistas, segundo as regiões do Estado do Sergipe. São Paulo, 2008

Tabela 17 - Raças bovinas predominantes nas propriedades de corte, leite e mistas, segundo as regiões do Estado do Sergipe. São Paulo, 2008

Tabela 18 - Mediana e quartis de fêmeas bovinas $\geq 24$ meses segundo tipo de exploração nas regiões do Estado de Sergipe. São Paulo, 2008 


\section{LISTA DE ABREVIATURAS E SIGLAS}

2-ME

AAT

DEAGRO/SE

EMATER

EMBRAPA

EMDAGRO

EUA

FMVZ

IA

IBGE

IC $95 \%$

MAPA

OIE

OR

PNCEBT

PRONASA

SEAGRI

$\mathrm{UnB}$

US\$

USP

VPS
2-Mercaptoetanol

Antígeno Acidificado Tamponado

Departamento de Desenvolvimento Agropecuário de Sergipe

Empresa de Assistência Técnica e Extensão Rural

Empresa Brasileira de Pesquisa Agropecuária

Empresa de Desenvolvimento Agropecuário de Sergipe

Estados Unidos da América

Faculdade de Medicina Veterinária e Zootecnia

Inseminação artificial

Instituto Brasileiro de Geografia e Estatística

Intervalo de confiança de $95 \%$

Ministério da Agricultura, Pecuária e Abastecimento

Organização Mundial de Saúde Animal, do inglês, World

Organization for Animal Health

Odds ratio, razão de chances

Programa Nacional de Controle e Erradicação da Brucelose e Tuberculose

Programa Nacional de Sanidade Animal

Secretaria de Estado da Agricultura e do Desenvolvimento Agrário

Universidade de Brasília

Dólar

Universidade de São Paulo

Departamento de Medicina Veterinária Preventiva e Saúde Animal 


\section{SUMÁRIO}

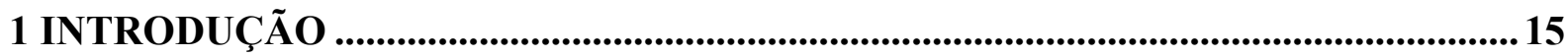

2 REVISÃO DE LITERATURA............................................................................18

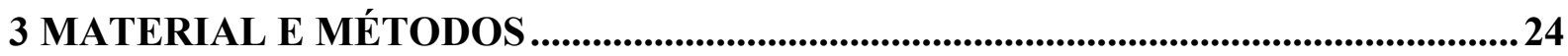

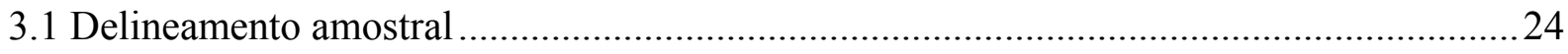

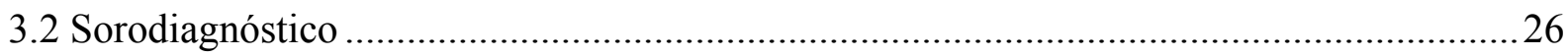

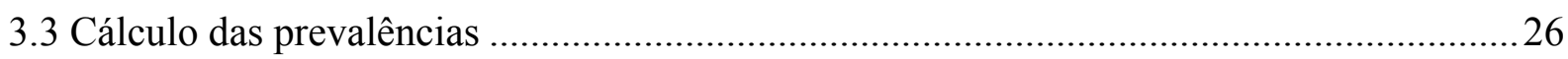

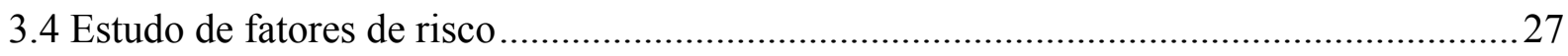

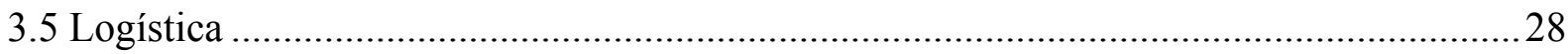

3.6 Caracterização dos circuitos produtores com base na amostra.............................................2

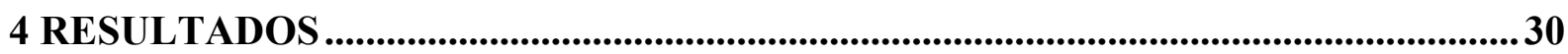

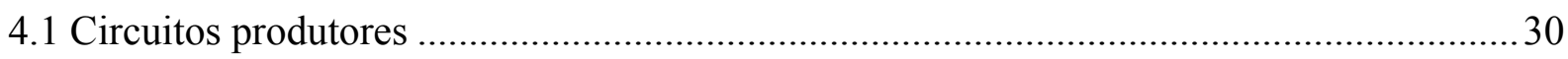

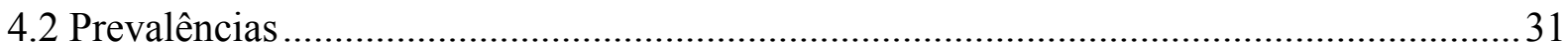

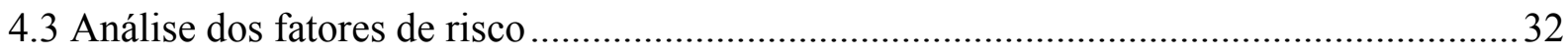

4.4 Caracterização dos circuitos produtores com base na amostra.............................................37

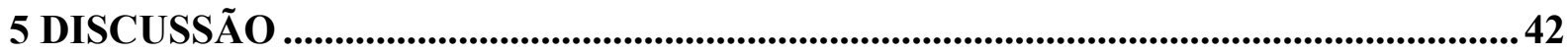

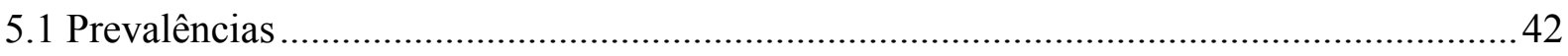

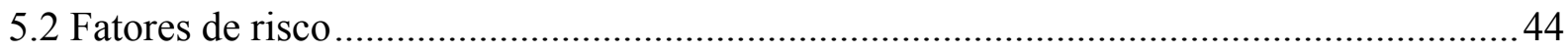

5.2.1 Fatores de risco para os dados consolidados para todo o Estado de Sergipe ...................44

5.2.2 Fatores de risco para o circuito produtor 1 do Estado de Sergipe .....................................45

5.2.3 Fatores de risco para o circuito produtor 2 do Estado de Sergipe .....................................46

5.3 Caracterização dos circuitos produtores com base na amostra............................................46

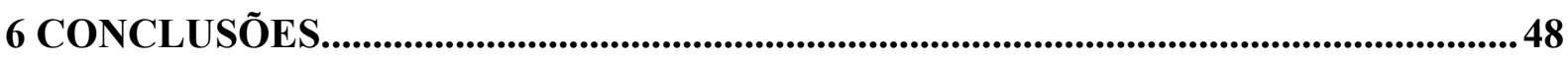

7 RECOMENDAÇÕES PARA O ESTADO..................................................................49 


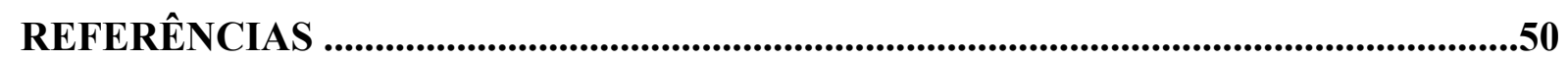

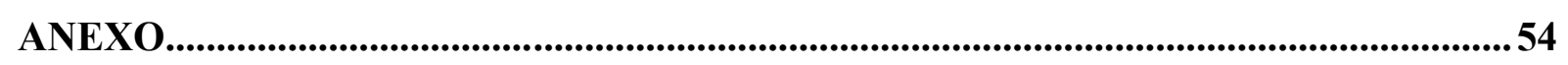




\section{INTRODUÇÃO}

O Estado de Sergipe localiza-se na região nordeste no Brasil, possui uma superfície de $22.005 \mathrm{~km}^{2}$, correspondendo a $0,26 \%$ do território nacional e é constituído por 75 municípios. Tem cerca de 1 milhão de cabeças de bovinos (IBGE, 2006a).

Segundo Dezen ${ }^{1}(2007)$, os principais responsáveis pela pecuarização do Estado foram os grandes produtores de bovinos de corte, com animais vindos do Estado da Bahia para o centro-sul do Estado e também para as regiões que margeiam o rio São Francisco (informação verbal). A Bovinocultura de corte desenvolveu-se na região da Cotinguiba, que abrange os municípios de Carmópolis, Divina Pastora, Japaratuba, Laranjeiras, Maruim, Nossa Senhora do Socorro, Rosário do Catete, Santa Rosa e Siriri. Também merecem destaque os municípios de Lagarto, Riachão do Dantas, Simão Dias, Pinhão, Pedra Mole, Aquidabã, Própria, Frei Paulo, Carira, Nossa Senhora das Dores, Cumbe, Feira Nova e Ribeirópolis (SEAGRI, 2007).

A produção de carne bovina é feita de forma extensiva, com pouco uso de inseminação artificial ou transferência de embriões. As raças mais utilizadas são o nelore, o tabapuã e seus mestiços (SEAGRI, 2007). A bovinocultura de leite desenvolveu-se na região do semi-árido, sendo o município de Nossa Senhora da Glória o maior produtor estadual.

Atualmente, o rebanho leiteiro é predominantemente do tipo misto (carne e leite), com tendência à especialização leiteira. $\mathrm{O}$ sistema de produção varia de extensivo a semi-intensivo (SEAGRI, 2007). A maior parte concentra-se nas mãos de pequenos produtores que dedicamse à fabricação de queijos. A indústria queijeira trouxe desenvolvimento e melhoria das condições de vida aos sertanejos da região, no entanto a maioria apresenta problemas de natureza sanitária e funciona de forma clandestina (SEAGRI, 2007).

\footnotetext{
${ }^{1}$ Informação fornecida por Dezen em Sergipe, em 2007.
} 
A primeira instituição a tratar dos assuntos agrários em Sergipe surgiu em 1915, através do Decreto n ${ }^{\circ}$ 608, que criou a Diretoria de Obras, Agricultura, Indústria e Aviação.

Em 1991, após várias reformas administrativas, a EMATER (Empresa de Assistência Técnica e Extensão Rural) passou a ser denominada de Empresa de Desenvolvimento Agropecuário de Sergipe (EMDAGRO), responsável pelas atividades de pesquisa agropecuária, sanidade animal e vegetal (SEAGRI, 2007). A partir de 2004 a denominação passou a ser Departamento de Desenvolvimento Agropecuário de Sergipe (DEAGRO/SE) (SEAGRI, 2007).

Segundo Dezen ${ }^{2}$ (2007), os primeiros registros de brucelose bovina no Estado deramse a partir de 1975, com o início do Programa Nacional de Sanidade Animal (PRONASA). Na maioria das vezes com a suspeita clínica seguida da confirmação pelos exames sorológicos específicos (informação verbal).

Nesse mesmo ano, o Ministério da Agricultura realizou o primeiro grande estudo de brucelose bovina no País, envolvendo 18 Estados. Sergipe foi incluído nesse estudo e apresentou uma prevalência nos animais de $10,5 \%$. O teste utilizado foi a Soro Aglutinação Rápida em Placa (BRASIL, 1977).

Em 1983, a EMBRAPA-Sergipe realizou um estudo visando conhecer a situação das doenças da esfera reprodutiva no rebanho do Estado, bem como verificar a eficiência do Card Test para o diagnóstico da brucelose bovina. Foram detectados $6,81 \%$ de animais positivos ao Card Test e 5,78\% animais positivos e 10,98\% suspeitos no teste de Soro Aglutinação Rápida em Placa (PEDREIRA et al., 1983).

Assim, como a brucelose ainda não está adequadamente caracterizada em todo Estado, o presente estudo teve por objetivos estimar as prevalências e conhecer os fatores de risco para a brucelose bovina, criando subsídios para a melhor implementação e gestão do

\footnotetext{
${ }^{2}$ Informação fornecida por Dezen em Sergipe, em 2007.
} 
Programa Nacional de Controle e Erradicação da Brucelose e Tuberculose (PNCEBT) em Sergipe. 


\section{REVISÃO DE LITERATURA}

A brucelose é uma doença que figura na lista de doenças de notificação obrigatória da Organização Mundial de Saúde Animal (OIE) e que atende à pelo menos dois critérios que justificam sua inscrição. É transmissível ao homem causando enfermidade crônica prolongada e em alguns países que possuem animais suscetíveis, não houve declaração de ocorrência de doença durante anos consecutivos. (OIE, 2008).

No Brasil, Schlogel (1966) estimou perdas anuais no valor de US\$ 6,65 milhões no Estado do Paraná pela brucelose bovina e suína. Em 1982 a Secretaria de Defesa Sanitária Animal do Brasil, estimou perda de aproximadamente US\$ 30,0 milhões (OIE, 1987).

Estima-se que as perdas por brucelose bovina na América Latina girem em torno de US\$ 600,00 a US\$ 700,00 milhões anuais (FARIA, 1984). Os Estados Unidos da América (EUA) estimaram em mais de US\$ 800 milhões anuais, as perdas decorrentes da doença, caso o programa de erradicação não tivesse sido criado (RICHEY; HARRELL, 1997).

A bactéria foi identificada no microscópio como agente causal de doença em 1886, por Sir David Bruce, médico da Real Marinha Britânica. No mesmo ano, na Dinamarca, Bang e Stribolt isolaram-na de bovinos pela primeira vez e denominaram-na de Bacillus abortus bovis (PACHECO; MELLO, $1956^{3}$ apud PAULIN; FERREIRA NETO, 2003).

A bactéria pertence ao gênero Brucella, cocobacilo curto e pleomórfico. É Gram negativa e cora-se bem pelo método Ziehl-Neelsen e Koster modificados (CARTER \& CHENGAPPA, 1991). Podem ser divididas antigenicamente em lisas (B. Abortus, B melitensis e B. suis) e rugosas (B. ovis e B. canis).

\footnotetext{
${ }^{3}$ PACHECO, G; MELLO, M.T. Brucelose. Livraria Ateneu, 727 p, 1956.
} 
A B. abortus aparece como principal agente etiológico da doença em bovinos e humanos. Os caprinos são acometidos principalmente pela $B$. melitensis. Suínos são naturalmente acometidos pela B. suis e também suscetíveis à infecção por B. abortus (VASCONCELLOS; ITO; CÔRTES, 1987), eventualmente, outros animais domésticos podem ser infectados e retransmitir a doença aos bovinos.

A infecção nos suínos por B. suis é transitória e pode por determinado período, servir como fonte de infecção para os bovinos (PAULIN; FERREIRA NETO, 2003). Os bovinos também podem se infectar pela B. suis, quando compartilham pastagens ou instalações com suínos infectados, embora seja raro. Os eqüinos são considerados elementos terminais na cadeia epidemiológica da brucelose por B. abortus (LYRA, 1984; PAULIN; FERREIRA NETO, 2003; VASCONCELLOS; ITO; CÔRTES, 1987).

Os cães são afetados de forma grave pela infecção por B. abortus e sua importância epidemiológica está ligada à disseminação do agente de forma mecânica, ao carrearem produtos do aborto pelas pastagens e entre fazendas (VASCONCELLOS; ITO; CÔRTES, 1987).

Nos seres humanos a doença aparece como de caráter ocupacional, infectando indivíduos que trabalham diretamente com os animais infectados, como magarefes, tratadores e veterinários (COSTA, 2001; DOGANAY; AYGEN, 2003).

As espécies unguladas silvestres são reservatórios naturais da Brucella abortus e responsáveis pela manutenção do agente no ambiente silvestre (PAULIN; FERREIRA NETO, 2003). No Brasil, Ito et all (1998) identificaram queixadas silvestres (Tayassu tajacu) sororreatoras à $B$. abortus. O agente já foi isolado de diversas espécies e em várias regiões, veados (Odocoileus virginianus e O. hemionus), alces (Alces alces), (BISHOP et all., 1994). Raposas vermelhas na Inglaterra (Dusicyon vulpis), coiotes (Canis latrans) no Texas 
(METCALF et All., 1994). Nos Estados Unidos da América (EUA), os bisões (Bison bison) e os cervos (Cervus canadensis) são os principais reservatórios silvestres.

A fonte de infecção na cadeia epidemiológica dos bovinos é a fêmea prenhe. Vacas não gestantes expostas ao agente podem desenvolver a condição de portadoras assintomáticas (PAULIN, FERREIA NETO, 2003). As principais vias de eliminação do agente são os fetos abortados e seus envoltórios e as descargas uterinas no momento do parto ou quando em abortamento, havendo contaminação das pastagens, água, alimentos e fômites, pois estes podem conter grandes quantidades do agente (ACHA; SZYFRES, 2001; NICOLETTI, 1980).

No leite de vacas infectadas, as brucelas começam a ser eliminadas por volta de duas semanas após o parto ou abortamento, e esta condição pode persistir por vários meses (ACHA; SZYFRES, 2001; PAULIN; FERREIRA NETO, 2003).

A via de transmissão mais freqüente é o contato indireto por ingestão de água e forragens contaminadas. O contato direto que ocorre quando a vaca lambe os anexos fetais e seu produto também constitui uma forma freqüente de transmissão. $\mathrm{O}$ ato de cheirar fetos abortados também possibilita a infecção, pois o agente pode penetrar pelas mucosas do nariz e dos olhos. Nos bovinos, a transmissão pelo coito não é de grande importância, pois o sêmen é depositado na vagina, onde as defesas inespecíficas dificultam o processo de infecção. A inseminação artificial aparece como importante via de transmissão e eficiente forma de difusão, uma vez que o sêmen contendo pequenas quantidades do agente é depositado diretamente no útero (ACHA; SZYFRES, 2001; PAULIN; FERREIRA NETO, 2003).

O sinal clínico predominante nas vacas de primeira cria pós-infecção é o abortamento em torno do sétimo mês de gestação. Em vacas brucélicas quando a gestação vem a termo, ocorre o nascimento de bezerros enfraquecidos ou natimortos. Nos machos a doença aparece como inflamação, aumento de volume uni ou bilateral dos epidídimos e testículos, podendo 
levar a subfertilidade, infertilidade ou esterilidade (ACHA; SZYFRES, 2001; PAULIN; FERREIRA NETO, 2003; VASCONCELLOS; ITO; CÔRTES, 1987).

A principal via de transmissão ao homem é através do consumo de leite e derivados sem tratamento térmico. O risco de contrair brucelose pela ingestão de carne bovina é baixo, pois as brucelas não são encontradas nos músculos desses animais e morrem quando submetidas a temperaturas utilizadas na culinária tradicional (MARTINS, $1994^{4}$ apud PAULIN; FERREIRA NETO, 2003).

A introdução de animais no rebanho é um dos fatores de risco mais importantes na epidemiologia da doença (SALMAN; MEYER, 1984). Quanto maior a frequência, maior é a chance de introduzir um animal infectado (CRAWFORD; HUBER; ADAMS, 1990). O aumento do tamanho do rebanho traz consigo um aumento da densidade dos animais, que propicia maior contato, favorecendo a difusão da infecção, principalmente em rebanhos mantidos em confinamento e após episódios de abortamento (NICOLETTI, 1980). A existência de rios ou açudes compartilhados entre propriedades distintas aumenta o risco de transmissão (ACHA; SZYFRES, 2001; NICOLETTI, 1998).

Os prejuízos decorrentes da brucelose estão relacionados a perdas de mercado, redução do valor dos animais, diminuição da produção de carne e leite, custo do tratamento da doença em humanos, além do afastamento do trabalho (BENENSON, 1983; GARCIACARRILO, 1975; GARCIA-CARRILO, 1990). Os transtornos reprodutivos levam à diminuição progressiva do rebanho em consequência à queda de natalidade (GRASSO, 2000). Estimativas mostram que a doença é responsável pela diminuição de 20 a $25 \%$ na produção de leite, 10 a $15 \%$ na de carne, aumento de $30 \%$ na taxa de reposição de animais e aumento do intervalo entre partos de 11,5 meses para 20 meses (ACHA; SZYFRES, 2001; FARIA, 1984; RADOSTITS et al., 2002).

\footnotetext{
${ }^{4}$ MARTINS, M. V. F. A. Brucella e os produtos alimentares de origem animal. Veterinária técnica, n. 2, p. 2023, 1994.
} 
Os programas de controle da brucelose bovina são preconizados desde 1896, no entanto foi a partir da década de 1930 que a sua implementação ocorreu em um maior número de países (PAULIN; FERREIRA NETO, 2003). Os motivos que levam à implementação de programas de controle e/ou erradicação se fundamentam na redução dos prejuízos econômicos e na importância em saúde pública. No Canadá, foi estimado um ganho de US\$ 5,00 para cada US\$1,00 investido, em 10 anos de programa (GARCIA-CARRILO, 1987). Na Itália para cada dólar investido, retornou-se 4,5 dólares (FERREIRA NETO, 1998).

A experiência internacional mostra que nas regiões de alta prevalência o combate à brucelose deve ser iniciado pela vacinação de fêmeas com B19. Uma cobertura vacinal de cerca de $80 \%$ das fêmeas em idade de procriar é capaz de rebaixar a prevalência a menos de 2\%. A segunda etapa do combate envolve a suspensão da vacinação e a intensificação da certificação das propriedades livres da doença, até a obtenção de $99,8 \%$ de propriedades certificadas como livre da brucelose, o que a OIE considera como área livre de brucelose. A área livre deve ser mantida através da renovação permanente dos certificados por rotina de testes e da estruturação de sistema de vigilância para detecção precoce e saneamento dos focos eventuais e resultantes da re-infecção de propriedades livres.

No Brasil, o Ministério da Agricultura, Pecuária e Abastecimento, instituiu em 2001 o Programa Nacional de Controle e Erradicação da Brucelose e Tuberculose (PNCEBT) visando à diminuição do impacto negativo dessas zoonoses na saúde humana e animal, além de promover a competitividade da pecuária nacional (LAGE et al., 2006). A Instrução Normativa SDA $n^{\circ} 6$ de 8 de janeiro de 2004, aprovou o regulamento técnico do programa, que se baseou na obrigatoriedade da vacinação de fêmeas de 3 a 8 meses de idade e na certificação por adesão voluntária de propriedades livres ou monitoradas.

Os objetivos específicos do programa são: reduzir a prevalência e a incidência de focos de brucelose e de tuberculose e criar um número significativo de propriedades 
certificadas como livre de brucelose e tuberculose ou monitoradas para brucelose e tuberculose e que ofereçam ao consumidor, produtos de baixo risco sanitário (LAGE et al., 2006).

O último diagnóstico de situação da brucelose bovina em nível nacional foi realizado em 1975, tendo sido estimada a porcentagem de animais soropositivos em 4\% na Região Sul, 7,5\% na Região Sudeste, 6,8\% na Região Centro-Oeste, 2,5\% na Região Nordeste e 4,1\% na Região Norte. Posteriormente, outros levantamentos sorológicos por amostragem, realizados em alguns Estados, revelaram pequenas alterações na prevalência da brucelose: no Rio Grande do Sul, a prevalência passou de $2 \%$ em 1975, para 0,3\% em 1986, após uma campanha de vacinação bem sucedida; em Santa Catarina, passou de 0,2\% em 1975, para 0,6\% em 1996. No Mato Grosso do Sul, a prevalência estimada em 1998 foi de 6,3\%, idêntica ao valor encontrado em 1975 para o território mato-grossense. Os dados de notificações oficiais indicam que a prevalência no Brasil se manteve entre 4 e 5\% no período de 1988 a 1998 (LAGE et al., 2006).

O conhecimento da situação epidemiológica da brucelose bovina é o primeiro passo quando se pretende implementar um programa de controle e erradicação, pois possibilita a escolha de estratégias adequadas que possibilitem o acompanhamento da evolução do programa evitando desperdício de tempo e recursos. 


\section{MATERIAL E MÉTODOS}

\subsection{Delineamento amostral}

Para se conhecer as diferenças regionais nos parâmetros epidemiológicos da brucelose bovina, o Estado foi dividido em circuitos produtores de bovinos, levando-se em consideração os diferentes sistemas de produção, práticas de manejo, finalidades de exploração, tamanho médio de rebanhos e sistemas de comercialização. A divisão do Estado em regiões correspondentes a circuitos produtores também levou em conta a capacidade operacional e logística do serviço veterinário oficial do Estado para a realização das atividades de campo, baseando-se nas áreas de atuação das suas unidades regionais.

Em cada circuito produtor, foi estimada a prevalência de propriedades infectadas pela brucelose bovina e de animais soropositivos através de um estudo amostral em dois estágios, dirigido a detectar focos da doença. No primeiro estágio foram sorteadas, de forma aleatória, um número pré-estabelecido de propriedades com atividade reprodutiva (unidades primárias de amostragem). No segundo estágio, dentro de cada propriedade, foi sorteado um número pré-estabelecido de fêmeas bovinas com idade igual ou superior a 24 meses (unidades secundárias de amostragem).

Nas propriedades rurais onde existia mais de um rebanho, foi escolhido como alvo do estudo o rebanho bovino de maior importância econômica, no qual os animais estavam submetidos ao mesmo manejo, ou seja, sob as mesmas condições de risco. A escolha da unidade primária de amostragem foi aleatória sistemática, baseada no cadastro de propriedades rurais com atividade reprodutiva de bovinos. Se uma propriedade sorteada não 
pôde, por quaisquer motivos, ser visitada, foi substituída por outra, nas proximidades e com as mesmas características de produção.

O número de propriedades selecionadas por circuito foi estimado pela fórmula para amostras simples aleatórias proposta por Thrusfield (2004). Os parâmetros adotados para o cálculo foram: nível de confiança de 0,95 , prevalência estimada de 0,25 e erro de 0,05 . A capacidade operacional e financeira do serviço veterinário oficial do Estado também foi levada em consideração para a determinação do tamanho da amostra por circuito.

O planejamento amostral para as unidades secundárias visou estimar um número mínimo de animais a serem examinados dentro de cada propriedade de forma a permitir a sua classificação como foco ou não foco de brucelose. Foram amostradas apenas fêmeas com idade igual ou superior a 24 meses. Para tanto, foi utilizado o conceito de sensibilidade e especificidade agregadas (DOHOO et al., 2003). Para efeito dos cálculos foram adotados os valores de $95 \%$ e $99,5 \%$, respectivamente, para a sensibilidade e a especificidade do protocolo de testes utilizado (FLETCHER et al., 1998) e 20\% para a prevalência intra-rebanho estimada. Nesse processo foi utilizado o programa Herdacc version 3 (University of Guelph, 1995) e o tamanho da amostra escolhido foi aquele que permitiu valores de sensibilidade e especificidade de rebanho iguais ou superiores a 90\%. Assim, nas propriedades com até 99 fêmeas com idade superior a 24 meses, foram amostrados 10 animais e naquelas com $100 \mathrm{ou}$ mais fêmeas com idade superior a 24 meses, foram amostrados 15 animais. A escolha das fêmeas dentro das propriedades foi casual sistemática. 


\subsection{Sorodiagnóstico}

O protocolo de testes de sorodiagnóstico foi composto por triagem com o teste do Antígeno Acidificado Tamponado (AAT) ou teste Rosa Bengala, seguida do reteste dos positivos com o teste do 2-Mercaptoetanol (2-ME), de acordo com as normas do PNCEBT (LAGE et al., 2006).

Uma propriedade foi considerada positiva quando ao menos um animal positivo foi detectado. As propriedades que apresentaram animais com resultado sorológico inconclusivo apenas, foram classificadas como suspeitas e excluídas das análises. O mesmo tratamento foi dado aos animais com resultados sorológicos inconclusivos.

\subsection{Cálculo das prevalências}

O planejamento amostral permitiu determinar as prevalências de focos e de fêmeas adultas ( $\geq 24$ meses) soropositivas para brucelose no Estado e também nos circuitos produtores. Os cálculos das prevalências aparentes e os respectivos intervalos de confiança foram realizados com o auxílio dos programas Excel $2003^{\circledR}$ e EpiInfo 6.04d (DEAN et al., 1994).

Os cálculos das prevalências de focos e de animais no Estado, e das prevalências de animais dentro das regiões foram feitos de forma ponderada, conforme preconizado por Dohoo et al. (2003). 
O peso de cada propriedade no cálculo da prevalência de focos no Estado foi dado por:

$P_{1}=\frac{\text { propriedades na região }}{\text { propriedades amostradas na região }}$

O peso de cada animal no cálculo da prevalência de animais no Estado foi dado por:

$P_{2}=\frac{\text { fêmeas } \geq 24 \text { meses na propriedade }}{\text { fêmeas } \geq 24 \text { meses amostradas na propriedade }} \times \frac{\text { fêmeas } \geq 24 \text { meses na região }}{\text { fềmeas } \geq 24 \text { meses nas propriedades amostradas na região }}$

Na expressão acima, o primeiro termo refere-se ao peso de cada animal no cálculo das prevalências de animais dentro das regiões.

\subsection{Estudo de fatores de risco}

Para cada um dos circuitos produtores e para os dados consolidados de todo o Estado, foi realizado um estudo de fatores de risco do tipo transversal. As variáveis analisadas foram: tipo de exploração (ou sistema de produção: carne, leite e misto), tipo de criação (confinado, semiconfinado, extensivo), uso de inseminação artificial, raças predominantes, número de vacas com idade superior a 24 meses, número de bovinos na propriedade, presença de outras espécies domésticas, presença de animais silvestres, destino da placenta e dos fetos abortados, compra e venda de animais, vacinação contra brucelose, abate de animais na propriedade, 
aluguel de pastos, pastos comuns com outras propriedades, pastos alagados, piquete de parição e assistência veterinária.

As categorias das variáveis foram organizadas de modo a apresentarem-se em escala crescente de risco, segundo informações da literatura (SALMAN et al., 1984; VASCONCELLOS et al., 1987; BEER, 1988; CRAWFORD et al., 1990; ACHA e SZYFRES, 2001; ITO et al., 1998; PAULIN; FERREIRA NETO, 2003;). Quando necessário, realizou-se a recategorização dessas variáveis. A categoria de menor risco foi considerada como base para a comparação das demais categorias. As variáveis quantitativas foram categorizadas em percentis.

Foi feita uma primeira análise exploratória dos dados (univariada) para seleção daquelas com $\mathrm{p} \leq 0,20$ para o teste do $\chi^{2}$ ou exato de Fisher (ZAR, 1999) e subseqüente oferecimento destas à regressão logística (HOSMER e LEMESHOW, 1989). Os cálculos foram realizados com o auxílio do programa SPSS 9.0 (SPSS INC., 1999).

\subsection{Logística}

O estudo foi planejado por técnicos do MAPA, USP e UnB e foi executado pelo DEAGRO-SE no período de outubro de 2002 a dezembro de 2003. Em cada propriedade amostrada, além da colheita de sangue para a sorologia, foi também aplicado o questionário epidemiológico, elaborado para obter informações sobre sua tipologia e práticas de manejo empregadas, de forma a permitir a realização do estudo de fatores de risco associados à presença da brucelose. 
As amostras de sangue foram colhidas dos animais por punção da veia jugular, utilizando agulha descartável estéril e tubo com vácuo previamente identificado. As amostras de soros obtidas foram armazenadas em micro tubos de plástico e congeladas a - $20^{\circ} \mathrm{C}$ até o momento da realização dos testes sorológicos.

Os testes sorológicos foram realizados no laboratório do Departamento de Desenvolvimento Agropecuário de Sergipe - DEAGRO/SE.

Todas as informações geradas pelo trabalho de campo e de laboratório (resultados dos testes sorológicos e questionário epidemiológico) foram inseridas em um banco de dados específico, utilizado nas análises epidemiológicas.

\subsection{Caracterização dos circuitos produtores com base na amostra}

Os circuitos produtores foram caracterizados utilizando-se a variável tipo de exploração como base para o cruzamento com outros dados obtidos através do questionário epidemiológico. Essa variável permitiu observar diferenças e semelhanças de algumas práticas e características, entre os rebanhos de corte, leite e misto e entre os circuitos.

As variáveis que permitiram detectar maiores ou menores graus de tecnificação e modernização de atividade entre os circuitos foram: tipos de criação, número de ordenhas por dia, tipo de ordenha, número de vacas em lactação, produção média de leite e produtividade leiteira (litros $/ \mathrm{n}^{\circ}$ de vacas em lactação), uso de inseminação artificial, raças bovinas predominantes e medianas de fêmeas bovinas $\geq 24$ meses.

Foram utilizados os programas SPSS 13.0 for Windows e Epiinfo 6.0 para o cálculo das freqüências e os intervalos de confiança de $95 \%$. 


\section{RESULTADOS}

\subsection{Circuitos produtores}

O Estado foi dividido em dois diferentes circuitos (Fig.1). Os dados censitários tomados como base para os cálculos da amostra foram os mais atualizados disponíveis à época do trabalho de campo, ou seja, no ano 2003. A Tab. 1 traz um resumo desses dados e a amostra estudada em cada um dos circuitos produtores.

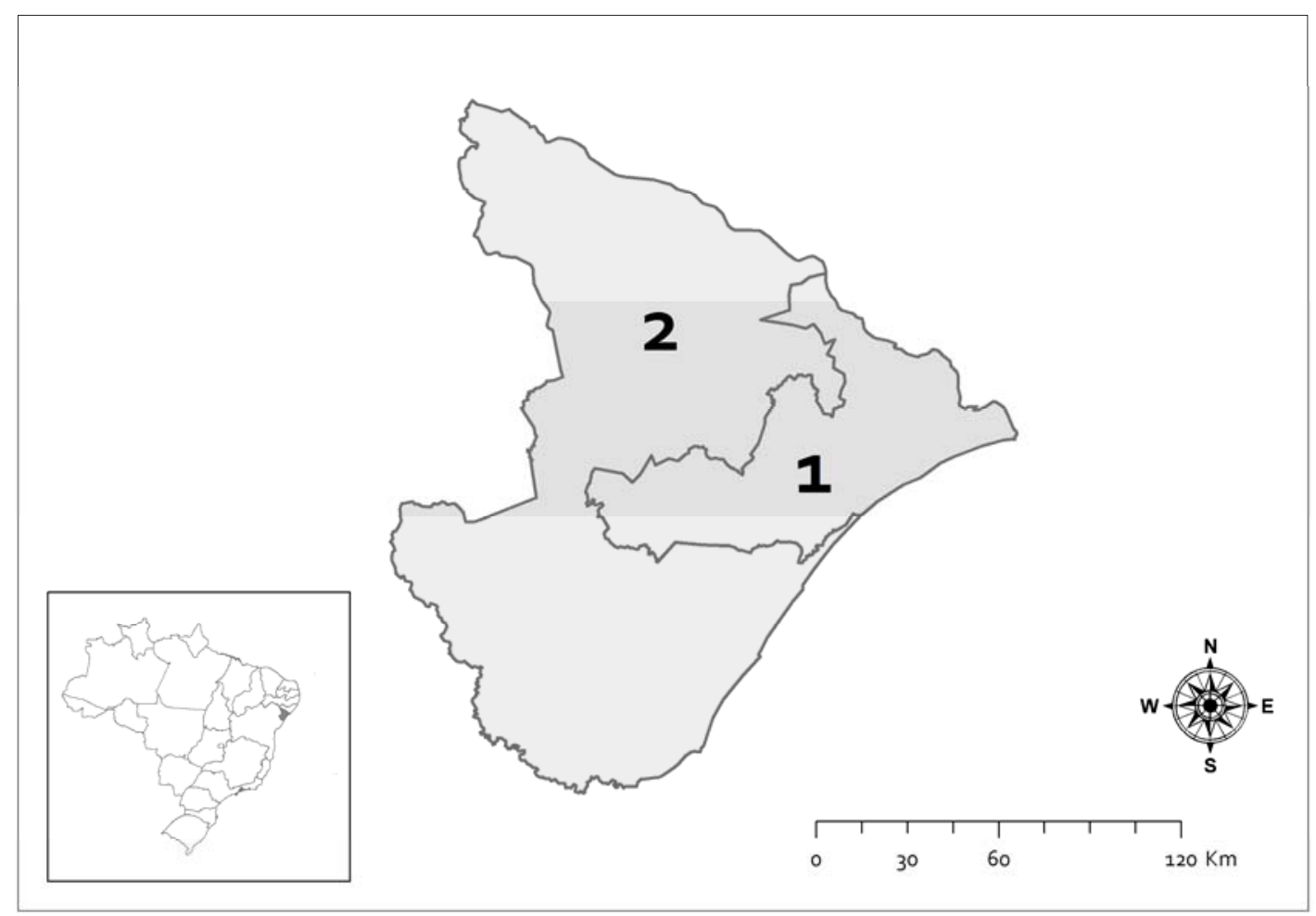

Mapa 1. Mapa do Estado de Sergipe com representação dos circuitos produtores. 
Tabela 1 - Dados censitários da população bovina do Estado de Sergipe em 2001, segundo os circuitos produtores (cadastro do DEAGRO). São Paulo, 2008.

\begin{tabular}{lcccc}
\hline Região & $\begin{array}{r}\text { propriedades com atividade reprodutiva } \\
\text { total }\end{array}$ & $\begin{array}{c}\text { fêmeas com idade } \geq 24 \text { meses } \\
\text { amostradas }\end{array}$ & $\begin{array}{c}\text { total } \\
\text { amostradas }\end{array}$ \\
\hline Leste & 3.582 & 328 & 262.442 & 2.620 \\
Oeste & 17.022 & 263 & 70.473 & 2.137 \\
\hline Total & $\mathbf{2 0 . 6 0 4}$ & $\mathbf{5 9 1}$ & $\mathbf{3 2 2 . 9 1 5}$ & $\mathbf{4 . 7 5 7}$ \\
\hline
\end{tabular}

\subsection{Prevalências}

Em 14 propriedades do circuito 1, os animais positivos ao teste AAT não foram submetidos ao teste confirmatório (2-ME). Essas propriedades foram consideradas focos. $\mathrm{O}$ mesmo fato ocorreu com 22 propriedades do circuito 2.

Todos os 49 animais positivos ao teste AAT que não foram submetidos ao teste confirmatório (2-ME) foram considerados como infectados e mantidos no cálculo das prevalências dos animais.

Embora existissem bubalinos no Estado no momento do trabalho de campo e os animais (bovinos e bubalinos) tenham sido selecionados aleatoriamente para participar da amostra, nenhum bubalino foi sorteado para participar da amostra.

A Tab. 2 mostra os resultados das prevalências de focos no Estado e nos circuitos produtores A Tab. 3 traz as prevalências de focos por tipologia das propriedades e a Tab. 4 as prevalências nos animais. 
Tabela 2 - Prevalência de focos de brucelose bovina nos circuitos produtores do Estado de Sergipe. São Paulo, 2008.

\begin{tabular}{ccccc}
\hline \multirow{2}{*}{ Circuitos Produtores } & \multicolumn{2}{c}{ Propriedades } & \multirow{2}{*}{ Prevalência (\%) } & \multirow{2}{*}{ IC 95\% (\%) } \\
\cline { 2 - 3 } & Testadas & Positivas & & \\
\hline $\mathbf{1}$ & 325 & 36 & 11,07 & {$[7,87-15,00]$} \\
$\mathbf{2}$ & 263 & 34 & 12,92 & {$[9,12-17,59]$} \\
\hline Total & $\mathbf{5 8 8}$ & $\mathbf{7 0}$ & $\mathbf{1 2 , 6 0}$ & {$[\mathbf{9 , 1 9}-\mathbf{1 6 , 0 1 ]}$} \\
\hline
\end{tabular}

Tabela 3 - Prevalência de focos de brucelose bovina, segundo o tipo de exploração nos circuitos produtores do Estado de Sergipe. São Paulo, 2008.

\begin{tabular}{ccccccc}
\hline \multirow{2}{*}{$\begin{array}{c}\text { Circuito } \\
\text { produtor }\end{array}$} & \multicolumn{5}{c}{ Prevalência de focos } \\
\cline { 2 - 7 } & $\mathbf{\%}$ & IC 95\% (\%) & $\mathbf{\%}$ & IC 95\% (\%) & $\mathbf{\%}$ & IC 95\% (\%) \\
\hline $\mathbf{1}$ & 7,14 & {$[0,87-23,50]$} & 14,74 & {$[9,58-21,29]$} & 7,80 & {$[3,95-13,53]$} \\
$\mathbf{2}$ & 9,52 & {$[2,65-22,62]$} & 13,40 & {$[7,33-21,82]$} & 13,70 & {$[8,19-21,04]$} \\
\hline
\end{tabular}

Tabela 4 - Prevalência de bovinos sororreagentes para brucelose nos circuitos produtores do Estado de Sergipe. São Paulo, 2008.

\begin{tabular}{ccccc}
\hline \multirow{2}{*}{ Circuito Produtor } & \multicolumn{2}{c}{ Animais } & \multirow{2}{*}{ Prevalência (\%) } & \multirow{2}{*}{ IC 95\% (\%) } \\
\cline { 2 - 3 } & Testados & Positivos & & \\
\hline 1 & 2.573 & 63 & 2,58 & {$[1,62-3,54]$} \\
2 & 2.067 & 71 & 6,25 & {$[3,00-9,49]$} \\
\hline Total & $\mathbf{4 . 6 4 0}$ & $\mathbf{1 3 4}$ & $\mathbf{3 , 3 6}$ & {$[\mathbf{2 , 2 8}-\mathbf{4 , 4 4}]$}
\end{tabular}

\subsection{Análise dos fatores de risco}

A Tab. 5 mostra os resultados da análise univariada e a Tab. 6 o modelo final da regressão logística para os dados consolidados para todo o Estado. 
Tabela 5 - Análise univariada dos possíveis fatores de risco para brucelose bovina em rebanhos com atividade reprodutiva no Estado de Sergipe. São Paulo, 2008.

\begin{tabular}{|c|c|c|c|}
\hline Variável & $\begin{array}{c}\text { Casos/ } \\
\text { Expostos }\end{array}$ & $\begin{array}{c}\text { Casos/Não } \\
\text { Expostos }\end{array}$ & $\chi^{2}$ \\
\hline Presença de ovinos e caprinos & $25 / 187$ & $45 / 401$ & 0,541 \\
\hline Presença de eqüídeos & $68 / 523$ & $2 / 65$ & 0,033 \\
\hline Presença de suínos & $17 / 109$ & $53 / 478$ & 0,251 \\
\hline Presença de aves & $43 / 340$ & $27 / 248$ & 0,602 \\
\hline Presença de cão & $45 / 396$ & $25 / 192$ & 0,656 \\
\hline Presença de gato & $37 / 274$ & $33 / 314$ & 0,322 \\
\hline Presença de animais silvestres & $27 / 204$ & $43 / 384$ & 0,554 \\
\hline Presença de cervídeos & $1 / 5$ & $69 / 583$ & $0,471^{*}$ \\
\hline Presença de capivaras & $0 / 3$ & $70 / 585$ & $1,0^{*}$ \\
\hline Presença de outros silvestres & $27 / 202$ & $43 / 386$ & 0,511 \\
\hline Comprar machos e fêmeas para reprodução & $39 / 333$ & $31 / 252$ & 0,929 \\
\hline Alugar pasto em alguma época do ano & $12 / 164$ & $58 / 423$ & 0,045 \\
\hline Utilizar pasto em comum com outras propriedades & $4 / 82$ & $66 / 506$ & 0,053 \\
\hline Presença de áreas alagadiças na propriedade & $27 / 159$ & $43 / 429$ & 0,030 \\
\hline Criação confinada ou semi confinada & $36 / 239$ & $34 / 349$ & 0,068 \\
\hline Ocorrência de aborto nos últimos 12 meses & $15 / 94$ & $54 / 475$ & 0,284 \\
\hline Ter assistência veterinária & $8 / 24$ & $62 / 564$ & $0,004 *$ \\
\hline Não realizar teste de brucelose & $56 / 506$ & $14 / 82$ & 0,169 \\
\hline Não utilizar piquete de parição & $46 / 426$ & $24 / 160$ & 0,210 \\
\hline Utilizar inseminação artificial & $10 / 40$ & $60 / 548$ & $0,019^{*}$ \\
\hline Destino impróprio para aborto & $29 / 259$ & $13 / 96$ & 0,673 \\
\hline Não vacinar ou vacinar fêmeas em qualquer idade com a B19 & $64 / 555$ & $6 / 31$ & $0,247^{*}$ \\
\hline Ter $\geq 30$ fêmeas com idade igual ou superior a 24 meses & $31 / 154$ & $37 / 427$ & 0,000 \\
\hline
\end{tabular}

* Corrigido pelo teste exato de Fisher. 
Tabela 6 - Modelo final da regressão logística multivariada para os fatores de risco para brucelose bovina em rebanhos com atividade reprodutiva no Estado de Sergipe. São Paulo, 2008.

\begin{tabular}{lccc}
\hline \multicolumn{1}{c}{ Variáveis } & OR & IC 95\% & Valor de p \\
\hline Ter $\geq 30$ fêmeas com idade igual ou superior a 24 & 1,88 & {$[1,07-3,28]$} & 0,026 \\
meses & 2,89 & {$[1,15-7,23]$} & 0,023 \\
Ter assistência veterinária & 1,92 & {$[0,84-4,38]$} & 0,117 \\
Utilizar inseminação artificial & & & \\
\hline $\mathrm{R}^{2}=0,084$ &
\end{tabular}

A Tab. 7 mostra os resultados da análise univariada e a Tab. 8 o modelo final da regressão logística para o circuito produtor 1 .

Tabela 7 - Análise univariada dos possíveis fatores de risco para brucelose bovina em rebanhos com atividade reprodutiva do circuito produtor 1 do Estado de Sergipe, 2003. São Paulo, 2008.

\begin{tabular}{lccc}
\hline \multicolumn{1}{c}{ Variável } & $\begin{array}{c}\text { Casos/ } \\
\text { Expostos }\end{array}$ & $\begin{array}{c}\text { Casos/Não } \\
\text { Expostos }\end{array}$ & $\chi^{2}$ \\
\hline Presença de ovinos e caprinos & $19 / 127$ & $17 / 198$ & 0,108 \\
Presença de eqüídeos & $34 / 282$ & $2 / 43$ & $0,195^{*}$ \\
Presença de suínos & $10 / 76$ & $26 / 249$ & 0,652 \\
Presença de aves & $27 / 236$ & $9 / 89$ & 0,887 \\
Presença de cão & $25 / 232$ & $11 / 93$ & 0,938 \\
Presença de gato & $21 / 167$ & $15 / 158$ & 0,479 \\
Presença de animais silvestres & $12 / 103$ & $24 / 222$ & 0,972 \\
Presença de cervídeos & $1 / 4$ & $35 / 321$ & $0,376^{*}$ \\
Presença de capivaras & $0 / 2$ & $36 / 323$ & $1,00^{*}$ \\
Presença de outros silvestres & $12 / 100$ & $24 / 225$ & 0,871 \\
Comprar machos e fêmeas para reprodução & $23 / 202$ & $13 / 122$ & 0,984 \\
Alugar pasto em alguma época do ano & $9 / 125$ & $27 / 172$ & 0,111
\end{tabular}


Tabela 7 - Análise univariada dos possíveis fatores de risco para brucelose bovina em rebanhos com atividade reprodutiva do circuito produtor 1 do Estado de Sergipe, 2003. São Paulo, 2008.

\begin{tabular}{lccc} 
Utilizar pasto em comum com outras propriedades & $3 / 65$ & $33 / 260$ & 0,102 \\
Presença de áreas alagadiças na propriedade & $13 / 72$ & $23 / 253$ & 0,054 \\
Criação confinada ou semi confinada & $23 / 172$ & $13 / 153$ & 0,222 \\
Ocorrência de aborto nos últimos 12 meses & $7 / 57$ & $28 / 262$ & 0,908 \\
Ter assistência veterinária & $2 / 6$ & $34 / 319$ & $0,135^{*}$ \\
Não realizar teste de brucelose & $31 / 277$ & $5 / 48$ & 1,00 \\
Não utilizar piquete de parição & $21 / 210$ & $15 / 113$ & 0,480 \\
Utilizar inseminação artificial & $4 / 12$ & $32 / 313$ & $0,033^{*}$ \\
Destino impróprio para aborto & $11 / 130$ & $7 / 46$ & $0,255^{*}$ \\
Não vacinar ou vacinar fêmeas em qualquer idade com a B19 & $33 / 312$ & $3 / 11$ & $0,112^{*}$ \\
Ter $\geq 26$ fêmeas com idade igual ou superior a 24 meses. & $17 / 83$ & $19 / 242$ & 0,003 \\
\hline
\end{tabular}

* Corrigido pelo teste exato de Fisher.

Tabela 8 - Modelo final da regressão logística multivariada para os fatores de risco para brucelose bovina em rebanhos com atividade reprodutiva do circuito produtor 1 do Estado de Sergipe. São Paulo, 2008.

\begin{tabular}{lccc}
\hline \multicolumn{1}{c}{ Variáveis } & OR & IC 95\% & Valor de p \\
\hline Ter $\geq$ 26 fêmeas com idade igual ou superior a 24 meses. & 2,99 & {$[1,46-6,13]$} & 0,003 \\
Utilizar inseminação artificial & 4,26 & {$[1,16-15,53]$} & 0,028 \\
Presença de áreas alagadiças na propriedade & 1,88 & {$[0,86-4,08]$} & 0,11 \\
\hline
\end{tabular}

$\mathrm{R}^{2}=0,093$

A Tab. 9 mostra os resultados da análise univariada e a Tab. 10 o modelo final da regressão logística para o circuito produtor 2 . 
Tabela 9 - Análise univariada dos possíveis fatores de risco para brucelose bovina em rebanhos com atividade reprodutiva do circuito produtor 2 do Estado de Sergipe. São Paulo, 2008.

\begin{tabular}{|c|c|c|c|}
\hline Variável & $\begin{array}{c}\text { Casos/ } \\
\text { Expostos }\end{array}$ & $\begin{array}{l}\text { Casos/Não } \\
\text { Expostos }\end{array}$ & $\chi^{2}$ \\
\hline Presença de ovinos e caprinos & $6 / 60$ & $28 / 203$ & 0,582 \\
\hline Presença de eqüídeos & $34 / 241$ & $0 / 22$ & $0,089 *$ \\
\hline Presença de suínos & $7 / 33$ & $27 / 229$ & $0,162 *$ \\
\hline Presença de aves & $16 / 104$ & $18 / 159$ & 0,440 \\
\hline Presença de cão & $20 / 164$ & $14 / 99$ & 0,790 \\
\hline Presença de gato & $16 / 107$ & $18 / 156$ & 0,533 \\
\hline Presença de animais silvestres & $15 / 101$ & $19 / 162$ & 0,586 \\
\hline Presença de cervídeos & $0 / 1$ & $34 / 262$ & $1,00^{*}$ \\
\hline Presença de capivaras & $0 / 1$ & $34 / 262$ & $1,00^{*}$ \\
\hline Presença de outros silvestres & $15 / 102$ & $19 / 161$ & 0,620 \\
\hline Comprar machos e fêmeas para reprodução & $16 / 131$ & $18 / 130$ & 0,835 \\
\hline Alugar pasto em alguma época do ano & $3 / 39$ & $31 / 224$ & 0,425 \\
\hline Utilizar pasto em comum com outras propriedades & $1 / 17$ & $33 / 246$ & $0,706^{*}$ \\
\hline Presença de áreas alagadiças na propriedade & $14 / 87$ & $20 / 176$ & 0,379 \\
\hline Criação confinada ou semi confinada & $13 / 67$ & $21 / 196$ & 0,105 \\
\hline Ocorrência de aborto nos últimos 12 meses & $8 / 37$ & $26 / 213$ & 0,200 \\
\hline Ter assistência veterinária & $6 / 18$ & $28 / 245$ & $0,018^{*}$ \\
\hline Não realizar teste de brucelose & $25 / 229$ & $9 / 34$ & $0,024 *$ \\
\hline Não utilizar piquete de parição & $25 / 216$ & $9 / 47$ & 0,245 \\
\hline Utilizar inseminação artificial & $6 / 28$ & $28 / 235$ & $0,227^{*}$ \\
\hline Destino impróprio para aborto & $18 / 129$ & $6 / 50$ & 0,921 \\
\hline Não vacinar ou vacinar fêmeas em qualquer idade com a B19 & $31 / 243$ & $3 / 20$ & $0,730^{*}$ \\
\hline Ter $\geq 26$ fêmeas com idade igual ou superior a 24 meses & $16 / 86$ & $18 / 177$ & 0,086 \\
\hline
\end{tabular}

* Corrigido pelo teste exato de Fisher. 
Tabela 10 - Modelo final da regressão logística multivariada para os fatores de risco para brucelose bovina em rebanhos com atividade reprodutiva do circuito produtor 2 do Estado de Sergipe. São Paulo, 2008.

\begin{tabular}{lccc}
\hline Variáveis & OR & IC 95\% & $\begin{array}{c}\text { Valor } \\
\text { de p }\end{array}$ \\
\hline Ter assistência veterinária & & & 0,012 \\
\hline
\end{tabular}

$\mathrm{R}^{2}=0,052$

\subsection{Caracterização dos circuitos produtores com base na amostra}

Os resultados da caracterização dos circuitos produtores estão contidos nas tabelas de 11 a 18.

Tabela 11 - Freqüência dos tipos de exploração em propriedades rurais segundo os circuitos produtores do Estado de Sergipe. São Paulo, 2008.

\begin{tabular}{|c|c|c|c|c|c|c|c|}
\hline \multirow{3}{*}{ Região } & \multicolumn{6}{|c|}{ Tipo de Exploração } & \multirow{3}{*}{$\begin{array}{c}\text { Total de } \\
\text { propriedades } \\
\text { amostradas }\end{array}$} \\
\hline & \multicolumn{2}{|r|}{ Corte } & \multicolumn{2}{|c|}{ Leite } & \multicolumn{2}{|r|}{ Misto } & \\
\hline & $\%$ & IC $95 \%(\%)$ & $\%$ & IC $95 \%(\%)$ & $\%$ & IC $95 \%(\%)$ & \\
\hline 1 & 8,62 & {$[5,80-12,21]$} & 48,00 & {$[42,45-53,58]$} & 43,38 & {$[37,92-48,96]$} & 325 \\
\hline 2 & 15,97 & {$[11,75-20,96]$} & 36,88 & {$[31,03-43,02]$} & 47,15 & {$[40,98-53,37]$} & 263 \\
\hline Total & 14,69 & {$[10,98-18,39]$} & 38,81 & {$[33,89-43,73]$} & 46,49 & {$[41,41-51,57]$} & 588 \\
\hline
\end{tabular}


Tabela 12 - Frequência dos tipos de criação nas propriedades de corte, leite e mistas, segundo as regiões do Estado do Sergipe. São Paulo, 2008.

\begin{tabular}{|c|c|c|c|c|c|c|c|}
\hline \multirow{3}{*}{$\begin{array}{l}\text { Tipo de } \\
\text { exploração e } \\
\text { região }\end{array}$} & \multicolumn{6}{|c|}{ Tipo de criação } & \multirow{3}{*}{$\begin{array}{c}\text { Total de } \\
\text { propriedades } \\
\text { amostradas }\end{array}$} \\
\hline & \multicolumn{2}{|c|}{ confinado } & \multicolumn{2}{|c|}{ semi-confinado } & \multicolumn{2}{|c|}{ extensivo } & \\
\hline & $\%$ & IC $95 \%(\%)$ & $\%$ & IC $95 \%(\%)$ & $\%$ & IC $95 \%(\%)$ & \\
\hline \multicolumn{8}{|l|}{ Corte } \\
\hline região 1 & 0,00 & {$[0,00-12,34]$} & 3,57 & {$[0,09-18,34]$} & 96,42 & {$[81,65-99,90]$} & 28 \\
\hline região 2 & 0,00 & {$[0,00-8,40]$} & 9,52 & {$[2,65-22,62]$} & 90,47 & {$[77,37-97,34]$} & 42 \\
\hline \multicolumn{8}{|l|}{ Leite } \\
\hline região 1 & 2,56 & {$[0,70-6,43]$} & 82,05 & {$[75,11-87,72]$} & 15,38 & {$[10,11-22,02]$} & 156 \\
\hline região 2 & 2,06 & {$[0,25-7,25]$} & 42,26 & {$[32,29-52,72]$} & 55,67 & {$[45,22-65,75]$} & 97 \\
\hline \multicolumn{8}{|l|}{ Misto } \\
\hline região 1 & 0,00 & {$[0,00-2,58]$} & 27,65 & {$[20,46-35,81]$} & 72,34 & {$[64,18-79,53]$} & 141 \\
\hline região 2 & 0,00 & {$[0,00-2,93]$} & 16,12 & {$[10,13-23,80]$} & 83,87 & {$[76,19-89,86]$} & 124 \\
\hline
\end{tabular}

Tabela 13 - Número de ordenhas por dia nas propriedades de leite e mistas, segundo as regiões do Estado do Sergipe. São Paulo, 2008.

\begin{tabular}{|c|c|c|c|c|c|}
\hline \multirow{3}{*}{$\begin{array}{c}\text { Tipo de } \\
\text { exploração }\end{array}$} & \multicolumn{4}{|c|}{ Número de ordenhas por dia } & \multirow{3}{*}{$\begin{array}{c}\text { Total de } \\
\text { propriedades } \\
\text { amostradas }\end{array}$} \\
\hline & \multicolumn{2}{|r|}{1} & \multicolumn{2}{|r|}{2 ou 3} & \\
\hline & $\%$ & IC $95 \%(\%)$ & $\%$ & IC $95 \%(\%)$ & \\
\hline \multicolumn{6}{|l|}{ Leite } \\
\hline região 1 & 79,73 & {$[72,49-85,79]$} & 20,26 & {$[14,20-27,50]$} & 153 \\
\hline região 2 & 92,39 & {$[84,94-96,88]$} & 7,60 & {$[3,11-15,05]$} & 92 \\
\hline \multicolumn{6}{|l|}{ Misto } \\
\hline região 1 & 99,05 & {$[94,85$ - 99,97] } & 0,94 & {$[0,02-5,14]$} & 106 \\
\hline região 2 & 90,78 & {$[81,93-96,21]$} & 9,21 & {$[3,78-18,06]$} & 76 \\
\hline
\end{tabular}

Tabela 14 - Freqüência dos tipos de ordenha nas propriedades de leite e mistas, segundo as regiões do Estado do Sergipe. São Paulo, 2008.

\begin{tabular}{|c|c|c|c|c|c|c|c|}
\hline \multirow{3}{*}{$\begin{array}{c}\text { Tipo de } \\
\text { exploração }\end{array}$} & \multicolumn{6}{|c|}{ Tipo de ordenha } & \multirow{3}{*}{$\begin{array}{c}\text { Total de } \\
\text { propriedades } \\
\text { amostradas }\end{array}$} \\
\hline & \multicolumn{2}{|c|}{ Manual } & \multicolumn{2}{|c|}{ Mecânica ao pé } & \multicolumn{2}{|c|}{$\begin{array}{c}\text { Mecânica em sala de } \\
\text { ordenha }\end{array}$} & \\
\hline & $\%$ & IC $95 \%(\%)$ & $\%$ & IC $95 \%(\%)$ & $\%$ & IC $95 \%(\%)$ & \\
\hline \multicolumn{8}{|l|}{ Leite } \\
\hline região 1 & 99,35 & {$[96,43-100,00]$} & 0,00 & {$[0,00-2,36]$} & 0,64 & {$[0,00-3,56]$} & 154 \\
\hline região 2 & 98,91 & {$[94,09-99,97]$} & 1,08 & {$[0,02-5,90]$} & 0,00 & {$[0,00-3,93]$} & 92 \\
\hline \multicolumn{8}{|l|}{ Misto } \\
\hline região 1 & 100,00 & {$[96,57-100,00]$} & 0,00 & {$[0,00-3,42]$} & 0,00 & {$[0,00-3,42]$} & 106 \\
\hline região 2 & 100,00 & {$[95,26-100,00]$} & 0,00 & {$[0,00-4,73]$} & 0,00 & {$[0,00-4,73]$} & 76 \\
\hline
\end{tabular}


Tabela 15 - Produtividade de leite nas propriedades de leite e mistas, segundo regiões do Estado do Sergipe. São Paulo, 2008.

\begin{tabular}{|c|c|c|c|c|c|c|c|}
\hline \multirow{3}{*}{$\begin{array}{l}\text { Tipo de } \\
\text { exploração e } \\
\text { região }\end{array}$} & \multicolumn{6}{|c|}{ Produtividade de leite } & \multirow{3}{*}{$\begin{array}{c}\text { Total de } \\
\text { propriedade } \\
\text { amostradas }\end{array}$} \\
\hline & \multicolumn{2}{|c|}{$N^{0}$ de vacas em lactação } & \multicolumn{2}{|c|}{$\begin{array}{c}\text { Produção diária de leite } \\
\text { (litros) }\end{array}$} & \multicolumn{2}{|c|}{$\begin{array}{c}\text { Produção média por animal } \\
\text { por dia (litros) }\end{array}$} & \\
\hline & Média & Desvio padrão & Média & Desvio padrão & Média & Desvio padrão & \\
\hline \multicolumn{8}{|l|}{ Leite } \\
\hline região 1 & 16,10 & $\pm 15,72$ & 94,58 & $\pm 113,07$ & 5,75 & $\pm 2,37$ & 156 \\
\hline região 2 & 15,84 & $\pm 15,17$ & 74,43 & $\pm 80,07$ & 5,02 & $\pm 2,68$ & 97 \\
\hline \multicolumn{8}{|l|}{ Misto } \\
\hline região 1 & 11,37 & $\pm 14,18$ & 49,02 & $\pm 63,15$ & 4,08 & $\pm 1,51$ & 141 \\
\hline região 2 & 14,45 & $\pm 21,99$ & 59,97 & $\pm 88,37$ & 5,13 & $\pm 4,66$ & 124 \\
\hline
\end{tabular}


Tabela 16 - Freqüência de uso de inseminação artificial em propriedades de corte, leite e mistas, segundo as regiões do Estado do Sergipe. São Paulo, 2008.

\begin{tabular}{|c|c|c|c|c|c|c|c|}
\hline \multirow{3}{*}{$\begin{array}{l}\text { Tipo de } \\
\text { exploração e } \\
\text { região }\end{array}$} & \multicolumn{6}{|c|}{ Uso de inseminação artificial (IA) } & \multirow{3}{*}{$\begin{array}{c}\text { Total de } \\
\text { propriedades } \\
\text { amostradas }\end{array}$} \\
\hline & \multicolumn{2}{|c|}{ Não usa } & \multicolumn{2}{|c|}{ IA + touro } & \multicolumn{2}{|c|}{ Apenas IA } & \\
\hline & $\%$ & IC $95 \%(\%)$ & $\%$ & IC $95 \%(\%)$ & $\%$ & IC $95 \%(\%)$ & \\
\hline \multicolumn{8}{|l|}{ Corte } \\
\hline região 1 & 100,00 & {$[87,65-100,00]$} & 0,00 & {$[0,00-12,34]$} & 0,00 & {$[0,00-12,34]$} & 28 \\
\hline região 2 & 73,80 & {$[57,96-86,13]$} & 23,80 & {$[12,05-39,45]$} & 2,38 & {$[0,06-12,56]$} & 42 \\
\hline \multicolumn{8}{|l|}{ Leite } \\
\hline região 1 & 93,58 & {$[88,52-96,88]$} & 4,48 & {$[1,82-9,02]$} & 1,92 & {$[0,39-5,51]$} & 156 \\
\hline região 2 & 90,72 & {$[83,11-95,66]$} & 7,21 & {$[2,95-14,30]$} & 2,06 & {$[0,25-7,25]$} & 97 \\
\hline \multicolumn{8}{|l|}{ Misto } \\
\hline região 1 & 98,58 & {$[94,97-99,82]$} & 0,00 & {$[0,00-2,58]$} & 1,41 & {$[0,17-5,02]$} & 141 \\
\hline região 2 & 93,54 & {$[87,68-97,17]$} & 5,64 & {$[2,29-11,28]$} & 0,80 & {$[0,02-4,41]$} & 124 \\
\hline
\end{tabular}

Tabela 17 - Raças bovinas predominantes nas propriedades de corte, leite e mistas, segundo as regiões do Estado do Sergipe. São Paulo, 2008.

\begin{tabular}{|c|c|c|c|c|c|c|c|c|c|c|}
\hline \multirow{3}{*}{$\begin{array}{l}\text { Tipo de } \\
\text { exploração e } \\
\text { região }\end{array}$} & \multicolumn{10}{|c|}{ Raça predominante } \\
\hline & \multicolumn{2}{|r|}{ Zebu } & \multicolumn{2}{|c|}{ Europeu de leite } & \multicolumn{2}{|c|}{ Europeu de corte } & \multicolumn{2}{|r|}{ Mestiço } & \multicolumn{2}{|c|}{ Outras raças } \\
\hline & $\%$ & IC $95 \%(\%)$ & $\%$ & IC $95 \%(\%)$ & $\%$ & IC $95 \%(\%)$ & $\%$ & IC $95 \%(\%)$ & $\%$ & IC $95 \%(\%)$ \\
\hline \multicolumn{11}{|l|}{ Corte } \\
\hline região 1 & 57,14 & {$[37,17-75,53]$} & 0,00 & {$[0,00-12,34]$} & 0,00 & {$[0,00-12,34]$} & 42,85 & {$[24,46-62,82]$} & 0,00 & {$[0,00-12,34]$} \\
\hline região 2 & 59,52 & {$[43,28-74,37]$} & 0,00 & {$[0,00-8,40]$} & 0,00 & {$[0,00-8,40]$} & 38,09 & {$[23,57-54,36]$} & 2,38 & {$[0,06-12,56]$} \\
\hline \multicolumn{11}{|l|}{ Leite } \\
\hline região 1 & 0,00 & {$[0,00-2,33]$} & 8,97 & {$[4,99-14,59]$} & 0,00 & {$[0,00-2,33]$} & 91,02 & {$[85,40-95,00]$} & 0,00 & {$[0,00-2,33]$} \\
\hline região 2 & 0,00 & {$[0,00-3,73]$} & 6,18 & {$[2,30-12,97]$} & 0,00 & {$[0,00-3,73]$} & 92,78 & {$[85,69-97,04]$} & 1,03 & {$[0,02-5,61]$} \\
\hline \multicolumn{11}{|l|}{ Misto } \\
\hline região 1 & 7,80 & {$[3,95-13,53]$} & 2,12 & {$[0,44-6,09]$} & 0,00 & {$[0,00-2,58]$} & 88,65 & {$[82,22-93,37]$} & 1,41 & {$[0,17-5,02]$} \\
\hline região 2 & 4,03 & {$[1,32-9,15]$} & 5,64 & {$[2,29-11,28]$} & 0,00 & {$[0,00-2,93]$} & 89,51 & {$[82,73-94,29]$} & 0,80 & {$[0,02-4,41]$} \\
\hline
\end{tabular}


Tabela 18 - Mediana e quartis de fêmeas bovinas $\geq 24$ meses segundo tipo de exploração nas regiões do Estado de Sergipe. São Paulo, 2008.

\begin{tabular}{|c|c|c|c|}
\hline \multirow{2}{*}{\multicolumn{2}{|c|}{$\begin{array}{l}\text { Tipo de exploração e } \\
\text { região }\end{array}$}} & \multicolumn{2}{|c|}{ Fêmeas $\geq 24$ meses } \\
\hline & & Mediana & $1^{\circ}$ e $3^{\circ}$ quartis \\
\hline \multicolumn{4}{|l|}{ Corte } \\
\hline & região 1 & 7,00 & {$[3,25-18,75]$} \\
\hline & região 2 & 12,50 & {$[5,00-39,25]$} \\
\hline \multicolumn{4}{|l|}{ Leite } \\
\hline & região 1 & 15,00 & {$[10,00-30,00]$} \\
\hline & região 2 & 14,00 & {$[7,25-31,75]$} \\
\hline \multicolumn{4}{|l|}{ Misto } \\
\hline & região 1 & 9,00 & {$[4,00-24,00]$} \\
\hline & região 2 & 10,00 & {$[4,00-34,00]$} \\
\hline
\end{tabular}




\section{DISCUSSÃO}

\subsection{Prevalências}

A prevalência de focos de brucelose bovina no Estado foi de 12,60 \% (Tab. 2). Os dados da Tabela 2 também mostram que as prevalências de focos nos circuitos são iguais, embora os valores pontuais sejam discretamente diferentes.

A Tabela 3 mostra que embora os valores pontuais das prevalências de focos sejam diferentes para as propriedades de tipo corte, leite e misto, não há diferença entre elas nos dois circuitos.

O circuito 1, formado principalmente por rebanhos de corte (SEAGRI, 2007), apresentou prevalências de focos para as propriedades do tipo leite e misto respectivamente de $14,74 \%$ e $7,80 \%$ (Tab. 3). Esse circuito abrange a região do vale do rio Cotinguiba, onde, em 1980, Pedreira et al. (1983) examinaram amostras de soro sanguíneo de 3.597 bovinos dos municípios de Capela, Japaratuba, Rosário do Catete, Siriri, Maruim, Riachuelo e Laranjeiras e classificaram $53,06 \%$ das propriedades que produziam leite como focos de brucelose. Esses autores utilizaram a Soroaglutinação Rápida em Placa e o Card Test e examinaram 50\% das propriedades com atividade leiteira. Dentro das propriedades, amostraram 50\% das matrizes e o total de machos reprodutores existentes. Os autores não informaram se resultados dos testes foram interpretados em série, em paralelo ou individualmente.

A prevalência de animais soropositivos à brucelose no Estado foi de 3,36 \% (Tab. 4), bem menor do que a verificada pelo Ministério da Agricultura em 1975 (10,5\%; BRASIL, 1977). 
Os dados da Tabela 4 também mostram que as prevalências nos animais nos circuitos são iguais, embora os valores pontuais sejam muito diferentes (Tab. 4). A prevalência nos animais encontrada no circuito 1 (2,5\%; Tab.4) foi inferior aos 6,8\% verificados por Pedreira et al. (1983) nos rebanhos leiteiros da região do vale do rio Cotinguiba.

Em resumo, a situação da brucelose no Estado é homogênea em relação aos circuitos e à tipologia das unidades de criação.

A comparação dos resultados do presente estudo com aqueles realizados em 1975 (BRASIL, 1977) e 1980 (PEDREIRA et al., 1983), em que pese a diferença de metodologia, tanto em relação ao protocolo de testes quanto ao delineamento amostral, sugere que a prevalência da doença tem diminuído com o passar dos anos, provavelmente resultado da melhoria das práticas sanitárias adotadas pelas cadeias produtoras de carne e leite. Entretanto, as prevalências de $12,6 \%$ de focos e de 3,36\% de animais (Tabs. 2 e 4) podem ser consideradas altas para uma doença de difusão lenta como a brucelose. O rebaixamento dessa prevalência pode ser conseguido através do aumento da cobertura vacinal com a estirpe B19.

Considerando apenas os valores pontuais, o fato do circuito 2 apresentar uma prevalência nos animais superior ao 1 (Tab. 4), sugere que a prevalência de animais soropositivos intra-rebanho no circuito 2 seja maior do que no circuito 1 .

Embora as Tabelas 2 e 4 mostrem diferenças nos valores pontuais das prevalências para os dois circuitos, o delineamento adotado não permitiu constatar diferenças.

Em relação à tipologia (Tab. 3), a doença está homogeneamente distribuída nos rebanhos de corte e leite em ambos os circuitos.

Assim, a brucelose bovina está homogeneamente distribuída nos dois circuitos do Estado de Sergipe e também nas propriedades tipo leite, carne e misto. 


\subsection{Fatores de risco}

\subsubsection{Fatores de risco para os dados consolidados para todo o Estado de Sergipe}

O modelo final da regressão logística apontou como fatores de risco as variáveis ter assistência veterinária e o tamanho do rebanho ( $\geq 30$ vacas). O uso da inseminação artificial, embora não tenha sido estatisticamente significante no modelo final, foi nele mantida como variável de ajuste, pois melhorou sua capacidade preditiva e mostrou um valor de $\mathrm{p}$ pouco superior a 0,1 (Tab. 6).

Há primeira vista, parece paradoxal que a existência de assistência veterinária signifique aumento de risco para a brucelose bovina. Porém, o que provavelmente ocorre no Estado é o hábito de se contratar serviços veterinários só após a constatação de transtornos reprodutivos, comumente associados à infecção brucélica. Assim, a assistência veterinária é uma conseqüência, não uma causa da presença da doença.

Quanto ao tamanho do rebanho, verificou-se que as propriedades com 30 ou mais vacas com idade igual ou superior a 24 meses $\left(2^{\circ}\right.$ tercil) tiveram uma chance 0,88 vezes maior de serem focos do que aquelas com um número menor de fêmeas (Tab. 6). Isso significa que a brucelose é mais freqüente nas propriedades maiores. Propriedades com rebanhos maiores praticam a reposição de animais com maior freqüência, expondo o rebanho ao risco constante de introdução da doença (CRAWFORD et al., 1990). Assim, essa variável está indiretamente associada à introdução de animais, fator de risco clássico para a brucelose bovina (SALMAN; MEYER, 1984). 
A inseminação artificial, quando praticada com sêmen de touros infectados é uma forma bastante eficiente de difundir a brucelose bovina, pois o sêmen é depositado diretamente no interior do útero, produzindo infecção com doses muito baixas de desafio (ACHA; SZYFRES, 2001; PAULIN; FERREIRA NETO, 2003). Assim, o verdadeiro problema é a prática de inseminação artificial sem cuidados sanitários, ou seja, sem a garantia de que o doador seja livre da infecção.

Concluindo, o Estado deve alertar os criadores sobre os riscos envolvidos na utilização da inseminação artificial e na introdução de animais sem cuidados sanitários.

\subsubsection{Fatores de risco para o circuito produtor 1 do Estado de Sergipe}

Quanto ao tamanho do rebanho, verificou-se que as propriedades com 26 ou mais vacas com idade igual ou superior a 24 meses $\left(2^{\circ}\right.$ tercil) tiveram uma chance 1,99 vezes maior de serem focos do que aquelas com um número menor de fêmeas (Tab. 8). O resultado é bem próximo do verificado para os dados consolidados de todo o Estado (Tab. 6).

A prática de inseminação artificial também aparece como fator de risco no circuito 1 (Tab. 8). As propriedades tiveram chance 3,26 vezes mais de serem focos do que aquelas que não a praticam.

A presença de áreas alagadiças se mostrou estatisticamente não significante, mas foi mantida como variável de ajuste, pois melhorou a capacidade preditiva do teste, indicando chance 0,88 vezes maior de serem focos as propriedades que relataram sua presença. De qualquer maneira, a presença de umidade aumenta a sobrevivência da brucela no ambiente, o que aumenta a probabilidade do agente infectar novo suscetível (PAULIN; FERREIRA 
NETO, 2003). Assim, drenar áreas alagadiças consiste em prática recomendável para a prevenção da brucelose no circuito produtor 1 .

\subsubsection{Fatores de risco para o circuito produtor 2 do Estado de Sergipe}

Para o circuito produtor 2, o resultado da análise multivariada foi semelhante ao resultado para os dados de todo o Estado, indicando a presença de assistência veterinária como fator de risco ( Tab 10, $\mathrm{OR}=3,87)$. Como já mencionado, a presença do veterinário é uma conseqüência, que pode indicar a presença da doença, pois o mesmo é chamado quando da ocorrência de transtornos reprodutivos que podem estar relacionados com a brucelose.

\subsection{Caracterização dos circuitos produtores com base na amostra}

A Tabela 11 mostra que os dois circuitos têm a mesma proporção de propriedades mistas, porém a proporção de propriedades de corte tende a ser maior na região 2 e a proporção de propriedades de leite tende a ser maior na 1 .

Nas duas regiões, a maioria das explorações de corte e mista é do tipo extensiva, enquanto que as de leite são majoritariamente semi-confinadas na região 1 e na região 2 mostram-se igualmente distribuídas entre os tipos semi-confinado e extensivo (Tabela 12).

A maioria das explorações de leite e mista faz apenas 1 ordenha por dia. A maior proporção de propriedades com 2 ordenhas ao dia foi verificada nos rebanhos de leite da 
região 1 (Tabela 13). A ordenha é quase que exclusivamente manual (Tabela 14) e a produção média por animal por dia é por volta de 4 a 6 litros (Tabela 15), correspondendo à média nacional, de 3,61 litros (IBGE, 2006b).

A maioria das propriedades, das três tipologias, não usa inseminação artificial. Quando usam, na maioria das vezes fazem o repasse posterior com touro. A freqüência de uso de inseminação artificial foi sempre superior nas propriedades de corte, leite ou mistas da região 2 (Tabela 16).

As propriedades de corte das regiões 1 e 2 apresentam as mesmas proporções de animais de raças zebuínas e mestiças. As propriedades de leite e mistas apresentam rebanhos prevalentemente mestiços (Tabela 17).

As propriedades do Estado são na sua maioria compostas por um pequeno número de matrizes. Para as propriedades de corte, a região 2 tende a ter um número de matrizes superior à 1 (Tabela 18).

Assim, em resumo, o Estado é composto por propriedades com um pequeno número de matrizes, na sua maioria de raças mestiças ou zebuínas, com níveis quase inexistentes de tecnificação. A produção de leite concentra-se mais na região 1 e a de carne na 2 . 


\section{CONCLUSÕES}

1) A situação da brucelose no Estado é homogênea em relação aos circuitos e à tipologia das unidades de criação.

2) As prevalências de focos e de animais são relativamente elevadas e o seu rebaixamento pode ser conseguido através do aumento da cobertura vacinal com a vacina $\mathrm{B} 19$.

3) No Estado, a condição de foco está associada à prática de inseminação artificial e à introdução de animais sem cuidados sanitários e à presença de áreas alagadas.

4) O Estado é composto por propriedades com um pequeno número de matrizes, na sua maioria de raças mestiças ou zebuínas, com níveis quase inexistentes de tecnificação. A produção de leite concentra-se mais na região 1 e a de carne na 2 . 


\section{RECOMENDAÇÕES PARA O ESTADO}

- Concentrar esforços na obtenção, em todos os anos, de uma cobertura vacinal mínima de $80 \%$ de fêmeas entre 3 e 8 meses de idade com a vacina B19.

- Desencorajar a utilização de inseminação artificial e introdução de animais sem cuidados sanitários e estimular a drenagem de áreas alagadas. 


\section{REFERÊNCIAS}

ACHA, P.N.; SZYFRES, B. Zoonosis y enfermedades transmisibles comunes al hombre y a los animales: bacterioses e micoses 3.ed. Washington: OPAS, 2001. 416p.

BEER, J. Doenças Infecciosas em Animais Domésticos. São Paulo: Roca, 1988. 380 p.

BENENSON, A. S. El control de las enfermidades transmisibles en hombre. Publicación Científica 442. Washington, D. C., OPAS, p. 31-33, 1983.

BISHOP, G. C.; BOSMAN, P.P.; HERR, S. Bovine brucellosis. In: COETZER, J. A.N.; THOMSON, G. R.; TUSTIN, R. C. (Editors). Infectious diseases of Livestock, v.2, Texas A\&M University Press, College Station, Austin, p. 1053-1066, 1994.

BRASIL. Ministério da Agricultura e Abastecimento. Diagnóstico de Saúde Animal, Brasília. 1977, 735 p.

CARTER, G. R.; CHENGAPPA, M. M. Brucella (cap. 24). Essentials of veterinary bacteriology and mycology. 4 ed. Philadelphia: London, p. 196-201, 1991.

COSTA, M. Brucelose bovina e equina. In: RIET-CORREA, F.; SCHILD, A. L.; MÉNDEZ, M. D. C.; LEMOS, R. R. A. Doenças de ruminantes e equinos. 2. Ed. São Paulo: Varela, 2001. v. 1, p. 187-197.

CRAWFORD, R. P.; HUBER, J. D.; ADAMS, B. S. Epidemiology and surveillance. In: NIELSEN, K.; DUNCAN, J. R. Animal brucellosis. Boca Raton: CRC Press, 1990. p. 131151.

DEAN, A. G.; DEAN, J. A.; COLOMBIER, D. et al. Epi-Info Version 6: a word processing database, and statistics program for epidemiology on microcomputers. Atlanta, CDC, 1994, $601 \mathrm{p}$.

DOGANAY, M.; AYGEN, B. Human brucellosis: an overview. International Journal of Infectious Diseases, v. 7, n. 3, p. 173-182, 2003.

DOHOO, I.; MARTIN, W.; STRYHN, H. Veterinary epidemiologic research. Charlottetown: AVC, 2003. 706p. 
EPIINFO 6.04d. Atlanta: Center for Diseases Control and Prevention, 2001. Disponível em: $<$ http://www.cdc.gov>. Acesso em: 23 out. 2007.

FARIA, J. F. Situação da brucelose no Brasil. Comunicações Científicas da Faculdade de Medicina Veterinária e Zootecnia da Universidade de São Paulo, v. 8, n. 2, p. 161-175, 1984.

FERREIRA NETO, J.S. Sobre a brucelose bovina no Estado de São Paulo. Biológico, v. 60, n. 2, p. 1-2, 1998.

FLETCHER, R. H.; FLETCHER, S. W.; WAGNER, E. H. Clinical epidemiology: the essentials. 2. ed. Baltimore: Williams \& Wilkins, 1998. 246p.

GARCIA-CARRILO, C. Animal and human brucellosis in the Américas. Paris: Office Internacional des Epizooties, 1990. 299 p.

GARCIA-CARRILO, C. Brucellosis. Programa de erradicacion em Califórnia. Argentina: Office Sanitária Panamericana, CPA/OMS, 1975. 173 p.

GARCIA-CARRILO, C. La brucellosis de los animales em América y su relación com La infección humana. Paris: Office Internacional dês Epizooties, 1987. 303 p.

GRASSO, L. M. P. S. O combate à brucelose bovina. 2000. 112 f. Dissertação (Mestrado em Medicina Veterinária) - Faculdade de Medicina Veterinária e Zootecnia, Universidade de São Paulo, São Paulo, 2000.

HERDACC, version 3. Guelph: University of Guelph, 2005. Disponível em:

$<$ http://www.vetschools.co.uk/EpiVetNet/FILES/herdacc.exe> Acessado em: 21 set. 2007.

HOSMER Jr, D. W.; LEMESHOW, S. Applied logistic regression. New York: Wiley, 1989. $307 \mathrm{p}$.

IBGE. Instituto Brasileiro de Geografia e Estatística. Pecuária 2006a. Disponível em: $<$ http://www.ibge.gov.br/estadosat/temas.php?sigla=se\&tema=pecuaria2006 $>$ Acesso em: 7 mai. 2007. 
IBGE. Instituto Brasileiro de Geografia e Estatística. Produção Pecuária Municipal Anual. 2006b. Disponível em < http://www.ibge.gov.br/servidor_arquivos_est/>. Acesso em 07 mai. 2007.

ITO, F. H.; VASCONCELLOS, S. A.; BERNARDI, F. et al. Evidencia sorológica de brucelose e leptospirose e parasitismo por ixodídeos em animais silvestres do Pantanal sulmatogrossense. Ars Vet., v. 14, n. 3, p. 302-310, 1998.

LAGE, A.P.; ROXO, E.; MÜLLER, E.; POESTER, F.; CAVALLÉRO, J.C.M.; FERREIRA NETO, J.S.; MOTA, P.M.P.C.; GONÇALVES, V.S.P. Programa Nacional de Controle e Erradicação da Brucelose e da Tuberculose Animal (PNCEBT). Manual Técnico. Ministério da Agricultura, Pecuária e Abastecimento, Brasília, 2006, 184p.

LYRA, T. M. P. Epidemiologia da brucelose. Comunicação Científica da Faculdade de Medicina Veterinária e Zootecnia da Universidade de São Paulo, São Paulo, v. 8, n. 2, p. 177-186, 1984.

METCALF, H. E.; LUCHSINGER, D. W.; RAY, W. C. Brucellosis. In: BERAN, G. W.; STEELE, J. H. (Editors). Handbook series in Zoonosis. Section A: Bacterial, Rickettsial, Chlamydial, and Mycotic. 2 ed. CRC Press, Boca Raton, p. 9-39, 1994.

NICOLETTI, P. Brucelose - as técnicas de controle. Imagem Rural Leite, v.5, n. 53, p. 9$12,1998$.

NICOLETTI, P. The epidemiology of bovine brucellosis. Advances in Veterinary Science and Comparative Medicine, v. 24, p. 69-98, 1980.

OIE. Brucellosis bovina, ovina y caprina. 1987, 282 p. (Série técnica n. 6).

OIE. Terrestrial animal health code. 17th ed. 2008. Disponível em:

$<$ http://www.oie.int/eng/normes/mcode/en_chapitre_1.1.2.htm>. Acesso em: 06 set. 2008.

PAULIN, L.M.; FERREIRA-NETO, J.S. O combate à brucelose bovina: Situação

Brasileira. Jaboticabal: Funep, 2003, 154p.

PEDREIRA, P.A.S.; OLIVEIRA, A.A.; ALMEIDA, M.F.R.S. Índice de ocorrência de brucelose bovina no Vale do Cotinguiba em Sergipe. Comunicado Técnico. Empresa Brasileira de Pesquisa Agropecuária, n.7, p. 1-4, 1983. 
RADOSTITS, O. M.; GAY, C. C.; BLOOD, D. C.; HINCHCLIFF, K. W. Clínica veterinária: um tratado de doenças dos bovinos, ovinos, suínos, caprinos e eqüinos. 9. Ed. Rio de Janeiro: Guanabara Koogan, 2002. 1.737 p.

RICHEY, E.J.; HARRELL, C. D. 1997. Brucella Abortus Disease (Brucellosis) in Beef Cattle. Disponível em: < http://edis.ifas.ufl.edu/document_vm026> Acesso em: 06 set. 2008.

SALMAN, M. D.; MEYER, M. E.; HIRD, D. W. Epidemiology of bovine brucellosis in the Mexicali Valley, México: data gathering and survey results. American Journal of Veterinary Research, v. 45, n.8, p. 1557-1560, 1984.

SCHLÖGEL, F. Aspectos econômicos da brucelose no Estado do Paraná. Separata dos Arquivos de Biologia e Tecnologia do Instituto de Biologia e Pesquisas. Impressora Paranaense S.S., Curitiba, v. XII, artigo 1, p. 5-10, 1966.

SEAGRI. Secretaria de Estado da Agricultura e do Desenvolvimento Agrário. Disponível em: <http://www.sagri.se.gov.br/modules/tinyd0/index.php?id=47>. Acesso em: 08 ag. 2007.

SPSS. SPSS base 9.0 user's guide. Chicago, 1999. $740 \mathrm{p}$

SPSS. SPSS base 9.0 user's guide. Chicago, 1999b. 1 CD-Rom.

THRUSFIELD, M. Epidemiologia Veterinária. 2. ed. São Paulo: ROCA, 2004. 556 p.

VASCONCELLOS, S.A.; ITO, F. H.; CÔRTES, J.A. Bases para a prevenção da brucelose animal. Comun. Ciên. Fac. Med. Vet. Zootec. USP, v. 11, n.1, p. 25-36, 1987.

ZAR, J. H. Bioestatistical analysis. 4. ed. Upper Saddle River: Prentice Hall, 1999. 663 p. 


\section{ANEXO A - QUESTIONÁRIO EPIDEMIOLÓGICO APLICADO NAS PEOPRIEDADES AMOSTRADAS}

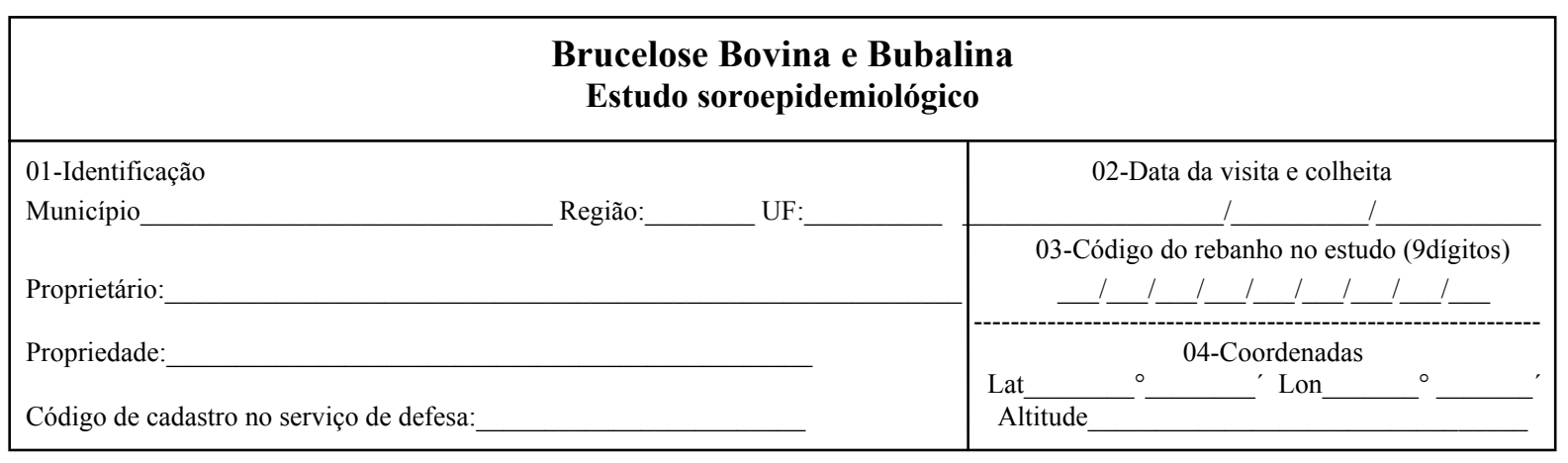

05- Tipo de exploração: $\square$ corte $\square$ leite $\square$ mista

06- Tipo de criação: $\square$ confinado $\square$ semi-confinado $\square$ extensivo

07- $\mathbf{N}^{\circ}$ de ordenhas por dia: $\square 1$ ordenha $\square 2$ ou 3 ordenhas $\square$ Não ordenha

08- Tipo de ordenha: $\square$ manual $\square$ mecânica ao pé $\square$ mecânica em sala de ordenha $\square$ Não ordenha

09- Produção de leite: a) $\mathrm{N}^{\circ}$ de vacas em lactação: $\quad$ b) Produção diária de leite na fazenda:

10- Usa inseminação artificial ? $\square$ não $\square$ usa inseminação artificial e touro $\square$ usa só inseminação artificial

11- Raça predominante - Bovinos: $\square$ zebu $\quad \square$ europeu de leite $\quad \square$ europeu de corte $\square$ mestiço $\square$ outras raças Bubalinos: $\square$ murrah $\square$ mediterrâneo $\square$ carabao $\square$ jaffarabadi $\square$ outras raças

\begin{tabular}{|c|c|c|c|c|c|c|c|c|c|c|c|c|c|c|}
\hline \multicolumn{7}{|c|}{12 (a) Bovinos existentes } & \multicolumn{8}{|c|}{12 (b) Bubalinos existentes } \\
\hline $\begin{array}{l}\text { Machos } \\
\text { castrades }\end{array}$ & \multicolumn{4}{|c|}{ machos inteiros (meses) } & \multicolumn{2}{|c|}{ fêmeas (meses) } & \multirow{2}{*}{$\begin{array}{c}\begin{array}{c}\text { Machos } \\
\text { castrados }\end{array} \\
\text { Total }\end{array}$} & \multicolumn{4}{|c|}{ machos inteiros (meses) } & \multicolumn{3}{|c|}{ fêmeas (meses) } \\
\hline Total & $0-6$ & $6-12$ & $12-24$ & $>24$ & $0-6$ 6-12 & $12-24 \quad>24$ & & $0-6$ & 6-12 & $12-24$ & $>24$ & 6-12 & $12-24$ & $>24$ \\
\hline & & & & & & & & & & & & & & \\
\hline
\end{tabular}

13- Outras espécies na propriedade: $\square$ ovinos/caprinos $\square$ eqüídeos $\square$ suínos $\square$ aves $\square$ cão $\square$ gato

14- Espécies silvestres em vida livre na propriedade: $\square$ não tem $\square$ cervídeos $\square$ capivaras $\square$ outras:

15- Alguma vaca/búfala abortou nos últimos 12 meses ? $\square$ não $\square \operatorname{sim} \quad \square$ não sabe

16- O que faz com o feto abortado e placenta ? $\square$ enterra/joga em fossa/queima $\square$ alimenta porco e cão $\square$ não faz nada

17- Faz testes para diagnóstico de brucelose ? $\square$ não $\square \operatorname{sim}$

Regularidade de teste: $\square$ uma vez ao ano $\quad \square$ duas vezes ao ano $\square$ quando compra animais

$\square$ quando há casos de aborto na fazenda $\square$ quando exigido para trânsito/eventos/crédito

18- Compra fêmeas ou machos com finalidade de reprodução ? $\square$ não $\square$ sim

Onde/dequem: $\square$ em exposição $\square$ em leilão/feira $\square$ de comerciante de gado $\square$ diretamente de outras fazendas

19 - Vende fêmeas ou machos para a reprodução ? $\square$ não $\square \operatorname{sim}$

Onde/dequem: $\square$ em exposição $\square$ em leilão/feira $\square$ de comerciante de gado $\square$ diretamente de outras fazendas

20-Vacina contra brucelose? $\square$ não $\square \operatorname{sim}$, apenas fêmeas até 8 meses de idade $\square \operatorname{sim}$, fêmeas de qualquer idade

21- Local de abate das fêmeas e machos adultos no fim da vida reprodutiva:

$\square$ na própria fazenda $\square$ em estabelecimento sem inspeção veterinária

$\square$ em estabelecimento de abate com inspeção veterinária $\square$ não abate

22- Aluga pastos em alguma época do ano? $\square$ não $\square$ sim

23- Tem pastos em comum com outras propriedades? $\square$ não $\square$ sim

24- Existem na propriedade áreas alagadiças às quais o gado tem acesso ? $\square$ não $\square \operatorname{sim}$

25- Tem piquete separado para fêmeas na fase de parto e/ou pós parto ? $\square$ não $\square \operatorname{sim}$

26- A quem entrega leite ? $\square$ cooperativa $\square$ laticínio $\square$ direto ao consumidor $\square$ não entrega

27- Resfriamento do leite: $\square$ não faz $\square$ faz Como: $\square$ em resfriador ou tanque de expansão próprio

28- A entrega do leite é feita a granel ? $\square$ não $\square$ sim

$\square$ em resfriador ou tanque de expansão coletivo

29- Produz queijo ou manteiga na propriedade? $\square$ não $\square \operatorname{sim}$ Finalidade: $\square$ p/ consumo próprio $\square$ / venda

30- Consome leite cru? $\square$ não $\square \operatorname{sim}$

31- Tem assistência veterinária ? $\square$ não $\square \operatorname{sim}$ De que tipo ? $\square$ veterinário da cooperativa $\square$ veterinário particular 


\begin{tabular}{|c|c|c|c|c|c|c|c|c|c|c|c|}
\hline \multicolumn{8}{|c|}{32 - INFORMAÇÕES SOBRE AS AMOSTRAS COLHIDAS } & \multicolumn{4}{|c|}{33 - RESULTADOS LABORATORIAIS (3) } \\
\hline $\mathbf{N}^{\circ}$ & $\begin{array}{c}\text { Número do frasco } \\
\text { Cód. do estudo }+\mathrm{N}^{\circ} \text { seqüencial } \\
(11 \text { dígitos })\end{array}$ & Espécie & $\mid \begin{array}{lc}\text { Idade } & \begin{array}{c}\mathrm{N}^{\circ} \mathrm{de} \\
\text { (anos) }\end{array} \\
\text { (pariçōes) }\end{array}$ & $\begin{array}{l}\text { Já abortou? } \\
\text { SIM NÂOO }\end{array}$ & BRU & $\begin{array}{l}\text { Vacinas } \\
\text { LEP. IBR }\end{array}$ & BVD & $\begin{array}{c}\text { AAT } \\
(+) \text { ou }(-)\end{array}$ & $\begin{array}{c}\text { SAL } \\
\text { (Título) }\end{array}$ & $\begin{array}{l}\text { 2-ME } \\
\text { (Título) }\end{array}$ & $\begin{array}{c}\text { Resultado final } \\
\text { (NEG) (INC) (POS) }\end{array}$ \\
\hline 1 & & & & & & & & & & & \\
\hline 2 & & & & & & & & & & & \\
\hline 3 & & & & & & & & & & & \\
\hline 4 & & & & & & & & & & & \\
\hline 5 & & & & & & & & & & & \\
\hline 6 & & & & & & & & & & & \\
\hline 7 & & & & & & & & & & & \\
\hline 8 & & & & & & & & & & & \\
\hline 9 & & & & & & & & & & & \\
\hline 10 & & & & & & & & & & & \\
\hline 11 & & & & & & & & & & & \\
\hline 12 & & & & & & & & & & & \\
\hline 13 & & & & & & & & & & & \\
\hline 14 & & & & & & & & & & & \\
\hline 15 & & & & & & & & & & & \\
\hline
\end{tabular}

Códigos e instrucões para preenchimento desta tabela

(1) Bovino $=1$; Bubalino = 2; (2) Marcar com X nas vacinas utilizadas (Bru = Brucelose; Lep = Leptospirose; IBR = Rinotraqueíte infecciosa bovina; $\mathrm{BVD}=\mathrm{Diarréia}$ viral dos bovinos)

(3) O resultado do Antígeno Acidificado Tamponado (AAT) pode ser : sem aglutinação ( - ) ou com algutinação ( + ); a prova confirmatória (2-ME) deve ser feita em soros reagentes (+) ao AAT, executando

simultaneamente a Soroaglutinação Lenta (SAL) e o 2-ME; o resultado final pode ser Negativo (NEG), Inconclusivo (INC) ou Positivo (POS), de acordo com a tabela de interpretação oficial, que consta do Capítulo

VI, do Regulamento Técnico do Programa Nacional de Controle e Erradicação da Brucelose e Tuberculose Animal.
34 - RESULTADO FINAL - CLASSIFICAÇÃO DA PROPRIEDADE:
$\square$ NEGATIVA
$\square$ INCONCLUSIVA
$\square$ POSITIVA 